\title{
A PROSPECTIVE STUDY OF PSYCHACHE AND ITS RELATIONSHIP TO SUICIDALITY
}

\author{
by \\ Talia Troister \\ A thesis submitted to the Graduate Program in Psychology \\ In conformity with the requirements for the \\ Degree of Doctor of Philosophy \\ Queen's University \\ Kingston, Ontario, Canada
}

April, 2014

Copyright (C) Talia Troister, 2014 


\begin{abstract}
Suicide takes the lives of over 3,500 Canadians each year, making prevention an important public health concern. Identifying psychological predictors of suicide risk is essential because these variables may be amenable to change in treatment, unlike demographic or historical factors. Although past research reveals that both hopelessness and depression are moderately strong predictors of suicidal outcomes, neither one of these constructs alone, or combined, is able to fully account for suicidality. Shneidman postulated that a different psychological construct, termed psychache, is a unique predictor of suicide when controlling for depression and hopelessness, and research has supported this assertion. Although evidence for psychache as a predictor of suicidal outcomes is accumulating, previous research has limitations, namely the use of cross-sectional research and a focus on healthy student populations. In addition, it has been suggested that because scales measuring depression, hopelessness, and psychache correlate highly, they are not distinct constructs, but instead represent a single syndrome.
\end{abstract}

The general purpose of the current studies is to establish the importance of psychache as a predictor of suicidal ideation. In order to address past limitations in the literature on psychache, three related studies were conducted. The first study was cross-sectional and examined a general group of undergraduate students. Factor analysis showed that psychache, depression, and hopelessness are three correlated, but distinct, variables. The second study was a longitudinal study where self-report measures were administered to high-risk undergraduate students. A twoyear follow-up revealed that psychache was the only significant predictor of suicidal ideation at follow-up, and that its inclusion rendered the predictive value of depression and hopelessness to nonsignificant levels. The final study involved two groups of undergraduates and was a 
longitudinal study with a five-month follow-up. One group was a general university sample, and the other was a group of high-risk students. The two groups were analyzed separately, but showed almost identical results, lending support to the generalization of results from university samples to clinical samples. In addition, for each group, psychache was a unique predictor of suicidal ideation and suicide preparation, after controlling for depression and hopelessness. Overall, these studies suggest that psychache is distinct from depression and hopelessness, and is a better predictor of suicidality than depression or hopelessness when studied longitudinally in both general and high-risk undergraduate students. The findings also indicate congruence between low and high-risk samples, highlighting the generalizability of psychache as a predictor. This research has implications for the assessment of suicide risk and treatment for individuals experiencing suicidal ideation. It is hoped that these studies will help bring psychache forward as a pre-eminent risk factor alongside depression and hopelessness. 


\section{Statement of Co-Authorship}

The first two manuscripts included in this dissertation are the result of collaboration between the doctoral candidate, Talia Troister, M.Sc., and her supervisor, Dr. Ronald R. Holden. As the primary author, Talia Troister was responsible for research conceptualization and design, as well as data collection, data analysis and the written dissertation. Dr. Holden assisted with all aspects of the study, in particular with data analysis and manuscript writing. In addition, Mike Davis and Ashley Lowndes collaborated on the third manuscript; specifically, they assisted with data collection. 


\section{Acknowledgments}

I'd like to take this opportunity to thank several people who contributed to the completion of this dissertation and to those who provided support and friendship throughout graduate school.

First and foremost, I would like to thank my supervisor, Dr. Ronald Holden. I have spent 7 years feeling lucky to be one of his students and could not have asked for a better supervisor. I've enjoyed our discussions of both research questions and travel destinations and have appreciated all his support and guidance. I'd also like to thank both Ron and Cynthia for creating a warm and comfortable lab environment.

I would also like to extend thanks to my committee members, Dr. Caroline Pukall and Dr. Leandre Fabrigar for their invaluable feedback as I completed my dissertation.

My graduate experience would not have been what it was without my colleagues in the clinical program. I'll miss Kingston eating, coffee shop work dates, and of course, Monday night reality television. I am lucky to have met such a supportive and fun group of people that I consider lifelong friends.

I am forever grateful to my family for their love and support. Thank you for your endless encouragement and belief in me. I wouldn't be where I am today without you. 


\section{Table of Contents}

CHAPTER 1 1

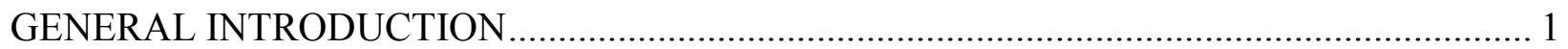

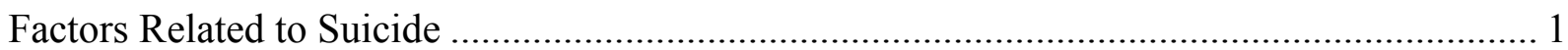

Depression and its Association with Suicidality .......................................................... 2

Hopelessness and its Association with Suicidality ..................................................... 3

Psychache and its Association with Suicidality......................................................... 4

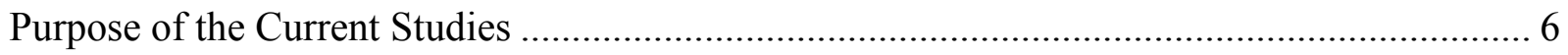

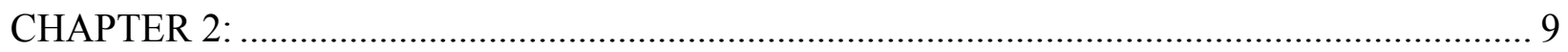

FACTORIAL DIFFERENTIATION AMONG DEPRESSION, HOPELESSNESS, AND ......... 9

PSYCHACHE IN STATISTICALLY PREDICTING SUICIDALITY ................................... 9

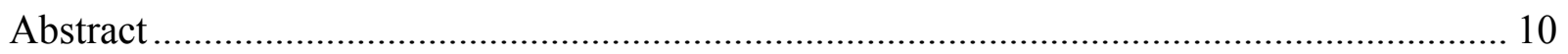

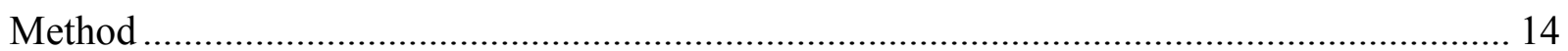

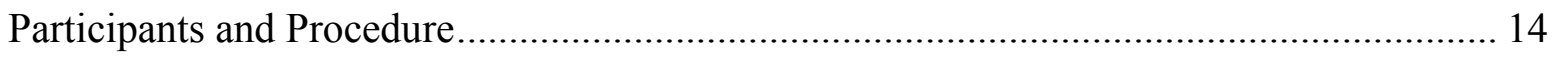

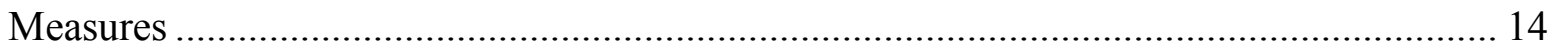

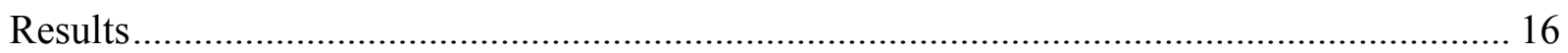

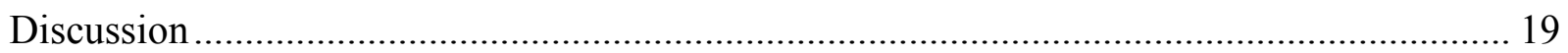

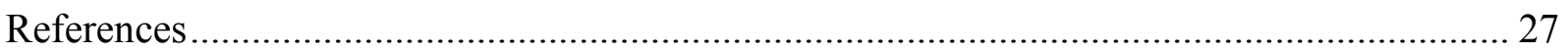

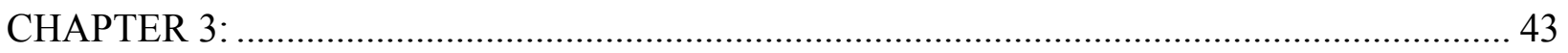

A TWO-YEAR PROSPECTIVE STUDY OF PSYCHACHE AND ITS RELATIONSHIP TO 43

SUICIDALITY AMONG HIGH-RISK UNDERGRADUATES ......................................... 43

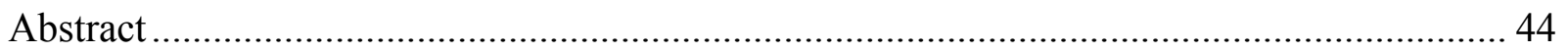

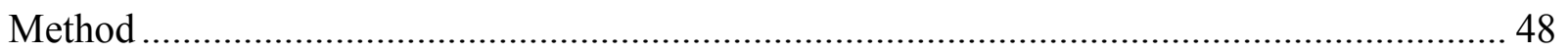

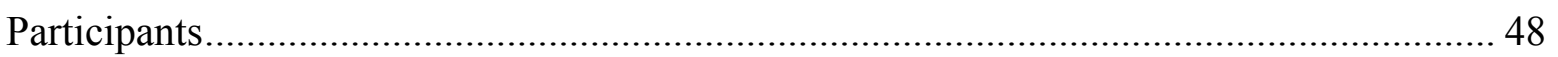

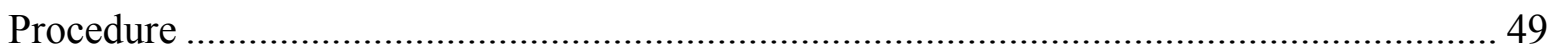

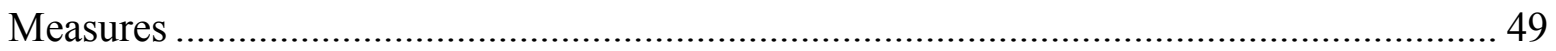

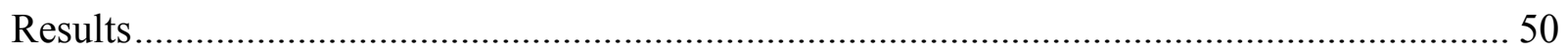

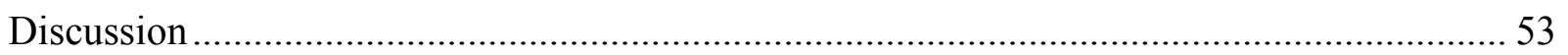

Limitations and Future Research ........................................................................ 55

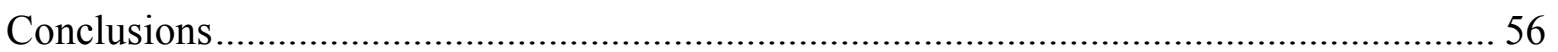

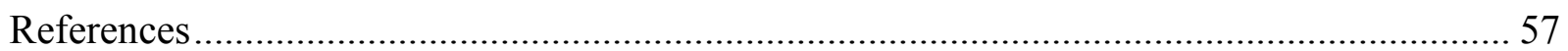

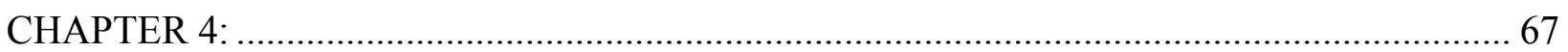

A FIVE-MONTH LONGITUDNAL STUDY OF PSYCHACHE AND SUICIDE IDEATION:67

REPLICATION IN GENERAL AND HIGH-RISK UNIVERSITY STUDENTS .................... 67 


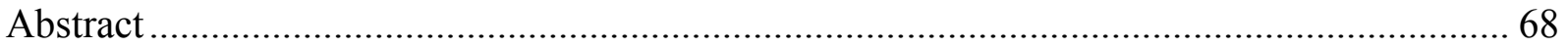

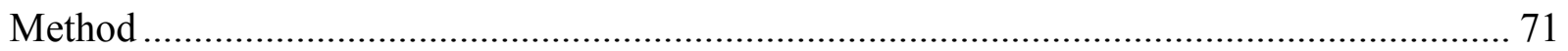

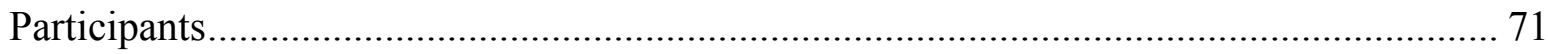

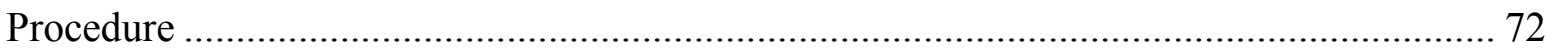

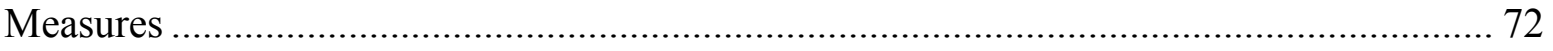

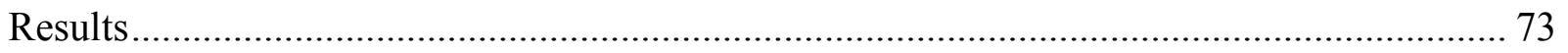

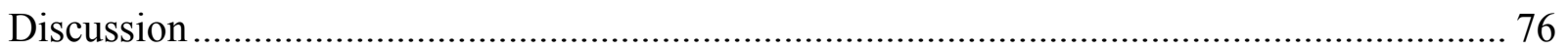

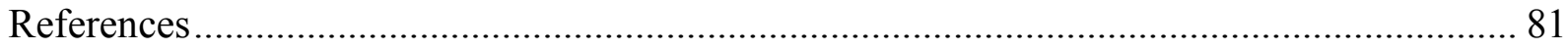

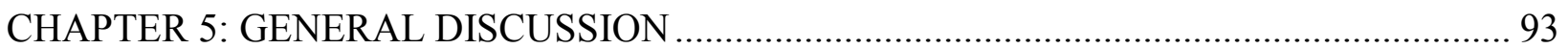

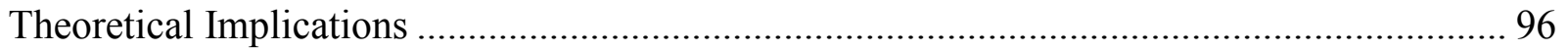

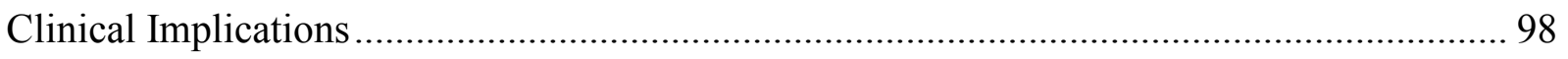

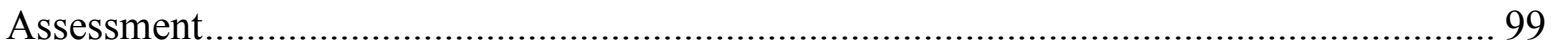

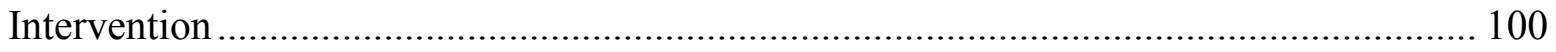

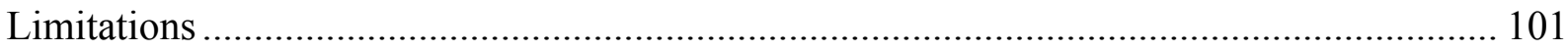

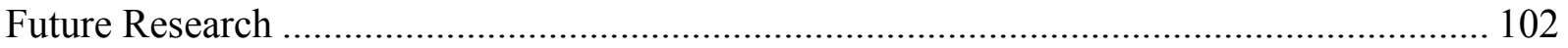

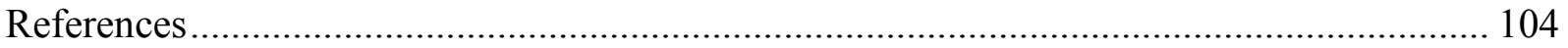

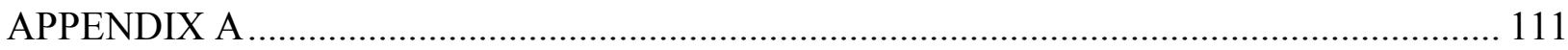


Chapter 2

\section{List of Tables}

Table 1: Scale Intercorrelations, Coefficient Alpha Reliabilities, Means, and Standard

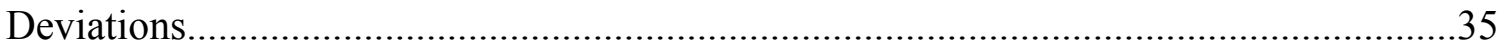

Table 2: Principal Component Loadings for Item Parcels..............................................37

Table 3: Standardized Regression Coefficients (General Dominance Weights, Relative Importance Weights) for Statistically Predicting Suicide Criteria from Promax-Rotated

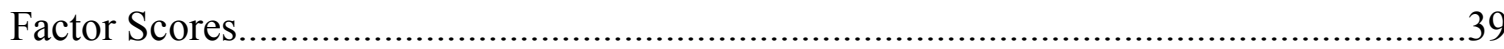

Chapter 3

Table 1: Means, Standard Deviations, Coefficient Alpha Reliabilities, t-tests, and Test-

Retest Reliabilities at Baseline and Two Year Follow-Up.......................................63

Table 2: Scale Intercorrelations at Baseline and Two Year Follow-Up.........................64

Table 3: Standardized Regression Coefficients for Statistically Predicting Suicide

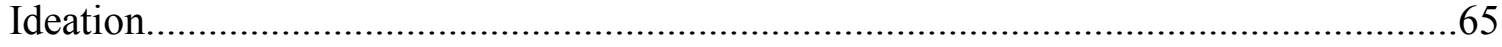

Table 4: General Dominance Weights and Relative Importance Weights for Statistically

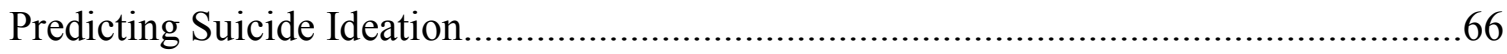

Chapter 4

Table 1: Scale Correlations, Means, and Standard Deviations $(\mathrm{N}=683$

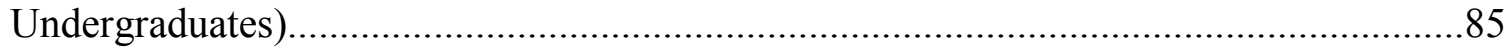

Table 2: Scale Correlations, Means, and Standard Deviations ( $\mathrm{N}=262$ High-Risk

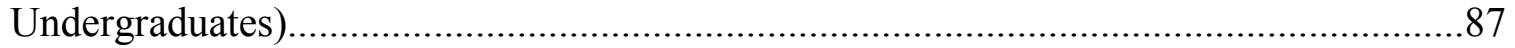

Table 3: Standardized Regression Coefficients for Statistically Predicting Change in

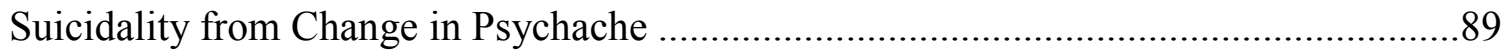


Table 4: Standardized Regression Coefficients for Predicting Change in Suicide Ideation from Change in Psychache Controlling for Change in Depression and Change in

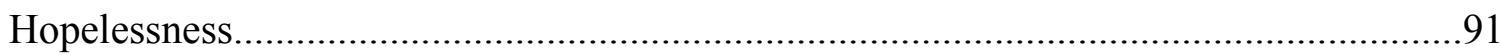

Appendix

Table 1: Standardized Regression Coefficients for Statistically Predicting Change in Suicidality from Change in Psychache Controlling for Change in Depression and Change in Hopelessness $(\mathrm{N}=98$ High-Risk Undergraduates)............................................111 


\section{List of Figures}

Chapter 2

Figure 1: Scree Plot for Item Parcel Components.................................................41

Figure 2: Confirmatory Factor Analysis (Standardized Solution).................................42 


\section{CHAPTER 1}

\section{GENERAL INTRODUCTION}

Research in the area of suicide has become critical in recent years. Suicide takes the lives of over 3,500 Canadians each year (Navaneelan 2012), and is one of the leading causes of death from adolescence to middle-age in both men and women. In the United States, approximately 85 individuals die by suicide every day (Moscicki, 1999), and suicide is one of the 10 leading cause of death in each of the U.S. (National Institute of Mental Health, n.d.), and Canada (Statistics Canada, 2011). Furthermore, it is estimated that for every death by suicide there are approximately 25 suicide attempts (Crosby et al., 2011). Worldwide, suicide claims the lives of almost one million people per year (World Health Organization, 2002). With such a surprisingly large number of people dying by suicide each year, suicide prevention is an important public health concern. Therefore, it is crucial that health researchers and practitioners are better able to identify who is at risk for suicide and to design effective intervention programs.

\section{Factors Related to Suicide}

Suicide prevention must begin with identification of who is at risk. In 1994, the Task Force on Suicide in Canada (Health Canada, 1994) called the identification of risk factors for suicide "one of the most vexing problems facing professionals in the health sciences" (p. xi). From demographic information, we know that men are three times more likely to die by suicide than are women (Statistics Canada, 2011), but that women are much more likely to attempt suicide (Moscicki, 2001). Research has also shown that suicide risk increases with age, and that whites are twice as likely as non-whites to die by suicide. Although this information is informative, it provides no sensitivity or specificity. Knowledge of demographic risk factors does 
not allow practitioners to properly assess their clients for suicide risk nor does it inform intervention.

Identifying psychological variables associated with suicidality is a promising avenue for assessing risk, because psychological factors can be targeted during interventions and may be amenable to treatment. The presence of a mental disorder provides the context for a large majority of attempted and completed suicides. Findings from the United States and Europe show that over $90 \%$ of individuals who die by suicide suffer from a mental or addictive disorder (Moscicki, 2001). A mood disorder is the diagnosis most commonly seen in those dying by suicide (Moscicki, 1999; Troister, Links, \& Cutcliffe, 2008).

Depression and its Association with Suicidality

Depression in particular has long been a well-recognized risk factor for suicide (Robins, Schmidt, \& O’Neil, 1959). A major depressive episode is the most common Axis I disorder diagnosed in individuals who eventually die by suicide, with some estimating that $87 \%$ of those who die by suicide have had a previous major depressive episode (Cheng, Chen, Chen, \& Jenkins, 2000). An abundance of research has supported the association between depression and suicidality. For example, one study of attempters showed that $80 \%$ scored in the depressed range on the Beck Depression Inventory (BDI), with a significant correlation found between the depth of depression and suicidal intent (Silver, Bohnert, Beck, \& Marcus, 1971). Longitudinal work found that risk of completed suicide was approximately three times higher in severely depressed people, as opposed to those with mild depression (Bradvick, Mattisson, Bogren, \& Nettelbladt, 2008). Prospective studies of suicide attempts found that a worsening of the course of major depressive disorder in the month prior to the attempt was predictive of an attempt (Yen, Shea, Pagano, Sanislow, Grilo, et al., 2003). Although it is evident that depression plays a role in 
suicide, not every depressed person is suicidal and not all suicide attempts occur during a depressive episode (Harkavy-Friedman, Nelson, Venarde, \& Mann, 2004).

\section{Hopelessness and its Association with Suicidality}

Hopelessness is another psychological factor found to have a central role in suicide (Beck \& Lester, 1973; Minkoff, Bergman, Beck, \& Beck, 1973; Wetzel, Marguiles, Davis, \& Karam, 1980). While investigating the nature of the relationship between depression and suicide, Aaron Beck recognized that the cognitive distortions prominent in depressed persons were most relevant to suicidal behaviour (Beck, 1963), and believed that affective symptoms were secondary. He noted that "Suicidal preoccupations...seemed related to the patient's conceptualization of his situation as untenable or hopeless" (p. 328). Subsequently, the study of hopelessness, or a negative view of the future (Beck), as a cause of suicide flourished. Numerous studies have found hopelessness to be an indicator of current suicide intent (Lester, Beck, \& Mitchell, 1979; Nekanda-Trepka, Bishop, \& Blackburn, 1983; Weishaar \& Beck, 1992).

There have also been a number of large-scale prospective studies examining the contributions of both depression and hopelessness to completed suicide. These investigations have shown that when hopelessness is statistically controlled, depression is no longer a significant predictor of completed suicide (Beck, Steer, Kovacs \& Garrison, 1985; Beck, Brown, \& Steer, 1989; Brown, Beck, Steer, \& Grisham, 2000). In a study of people admitted to hospital for suicidal ideation, only hopelessness and the pessimism item of the Beck Depression Inventory (BDI) predicted eventual suicide. In this study, a score of 10 or more on the Beck Hopelessness Scale (BHS) identified 91\% of suicides (Beck, Steer, Kovacs \& Garrison, 1985). However, many individuals with a score of 10 or more did not go on to die by suicide, showing that hopelessness cannot fully account for suicidality. 
It is clear from a plethora of literature that both hopelessness and depression are moderately strong predictors of who will attempt, and die by, suicide (Lester, Beck, \& Mitchell, 1979; Thompson, Mazza, Herting, Randell, \& Eggert, 2005). However, research has also revealed that neither one of these constructs alone or combined is able to fully account for and/or predict suicidality. It is clear that not all depressed people die by suicide, not all people who die by suicide are clinically depressed (Baumeister, 1990), and hopelessness alone cannot be used to predict suicide risk.

Psychache and its Association with Suicidality

Although both depression and hopelessness have received abundant support as psychological predictors of suicidality, another variable is emerging as an important predictor. Edwin Shneidman, a prominent researcher in the area of suicidology, proposed that psychological pain, or psychache, is necessary and sufficient for suicide to occur, and that it mediates the effects of all other factors, such as depression and hopelessness, in their association with suicide (Shneidman, 1993). Shneidman defines psychache as the "hurt, anguish, soreness, aching, psychological pain in the psyche, the mind" (Shneidman, 1993, p. 145). He argued that all other factors are secondary, and only important to suicide insofar as their association with psychache. For an individual to die by suicide, Shneidman states that the perception of the pain must be unbearable for that person, and that stopping the pain by stopping consciousness is perceived as the only solution. Therefore, suicide is considered the only means to escape the intensely felt psychache. He postulated that if the pain can be relieved, the individual would be willing to continue to live (Shneidman, 1984).

Support for psychache as a factor in suicide has been increasing in recent years.

Examination of suicide notes reveals that wanting to escape from unbearable psychological pain 
is a common theme (Leenaars, 1991; Valente, 1994). Worst-ever psychache is associated with both current depression and a history of suicidal ideation (Lester, 2000). Holden, Mehta, Cunningham, and McLeod (2001) operationalized psychache, developing the 13-item Psychache Scale based on Shneidman's (1993) definition of psychological pain. As measured by the Psychache Scale, psychache has been shown to be a significant predictor of suicidal ideation in university students (Flynn \& Holden, 2007; Holden et al., 2001; Troister \& Holden, 2010) and to be correlated with suicide attempter status in a group of offenders (Mills, Green, \& Reddon, 2005). In a group of offenders and university students, psychache was more important than either depression or hopelessness as a statistical predictor of suicidality (Pereira, Kroner, Holden, \& Flamenbaum, 2010).

Research has also supported Shneidman's assertion that the relationship of other factors with suicide is mediated by psychache. DeLisle and Holden (2009) found good fit for a model in which psychache mediated the effects of hopelessness and depression on suicidality, and found psychache to be the most proximal factor associated with suicidality. Psychache has also been shown to fully mediate the relationship between perfectionism and suicidality (Flamenbaum \& Holden, 2007) and between alexithymia and suicidality (Keefer, Holden, \& Gillis, 2009). In a group of mood-disordered outpatients, psychache (as measured by psychological quality of life) was shown to have a unique relationship to suicidality that was not accounted for by the other psychological variables (Berlim et al., 2003), consistent with Shneidman's perspective on suicidality.

It is evident from current literature that empirical support for psychache as a psychological variable relevant for suicidality is accumulating. Additional research is necessary to bring it forward as a pre-eminent predictor of suicide risk, and to show that psychache merits 
consideration alongside depression and hopelessness as a psychological predictor of suicide. A primary issue for the status of psychache is that the majority of research examining psychache has been cross-sectional in design, limiting the ability to draw causal inferences. Although crosssectional research can test a priori causal models such as Shneidman's assertion that psychache causes suicide, such designs have limitations for uncovering causal links. Does psychache cause suicidality, does suicidality cause psychache, or does a third variable cause both psychache and suicidality? These questions have yet to be fully answered. Researchers have also suggested that suicidal ideation, depression, and hopelessness are all part of one single syndrome that predicts suicide risk, and are not in fact separate predictors (Shahar, Bareket, Rudd, \& Joiner, 2006). Although some research has supported the notion that psychache is separate from depression and hopelessness (DeLisle \& Holden, 2009), more research is needed to demonstrate its distinctiveness.

Another consideration is that most researchers examining psychache have drawn samples from a population of undergraduate students who are considered to be a relatively healthy group. Although research on depression has shown consistency between analogue and clinical samples (Vredenburg, Flett, \& Krames, 1993), the generalizability of current findings to clinical or other populations remains to be confirmed. To date, there has been research examining psychological pain in suicide attempters (Flynn \& Holden, 2007), and in mood-disordered outpatients (Berlim et al., 2003), but more research with at-risk groups is required.

\section{Purpose of the Current Studies}

The general purpose of the current studies was to examine the predictive value of psychache to suicidality, over and above depression and hopelessness. The first study was crosssectional and involved a large group of undergraduates completing self-report questionnaires in 
order to confirm that psychache is a unique variable from depression and hopelessness. Both exploratory and confirmatory factor analysis were used in order to establish the construct validity of these variables and the distinctiveness of psychache. In addition, factor scores were used to test whether these psychological predictors have added value in predicting suicidal ideation and to establish the prominence of psychache over depression and hopelessness in predicting suicide ideation. This study extended past research by using a large sample size to demonstrate the independence of these psychological variables. This is also the first study to demonstrate the construct validity of these psychological variables by demonstrating their differential relevance for statistically predicting separate suicide criterion, and by directly comparing regression coefficients.

The second study used in-class and online self-report measures and involved a two-year follow-up with individuals who were at relatively high risk for suicidal behaviours. The study examined whether, over this two-year period, psychache was a better predictor of suicide ideation than either depression or hopelessness. Prior to this study, there had been no published longitudinal research examining psychache alongside both depression and hopelessness. In addition, any prospective study that was conducted had utilized a general undergraduate population. Therefore, this study expands upon current literature by: 1) being the longest followup study conducted to date that examines psychache; and 2) by using a relatively high-risk group of students as opposed to a general undergraduate sample.

The third study also used online questionnaires to examine both a general student population and a higher risk student population over a five-month period. This study was another opportunity to demonstrate the prominence of psychache over depression and hopelessness in its ability to statistically predict suicide ideation, and did so with a large sample. This larger sample 
allowed for the use of a more well-established data analysis technique and therefore added more weight and reliability to the importance of psychache. In addition, by using two populations, a comparison could be made between results for the general and higher risk samples to show that results on undergraduates mirror findings obtained when using a more clinical sample. This type of comparison had not previously been undertaken with the inclusion of psychache. 
CHAPTER 2:

FACTORIAL DIFFERENTIATION AMONG DEPRESSION, HOPELESSNESS, AND PSYCHACHE IN STATISTICALLY PREDICTING SUICIDALITY 


\begin{abstract}
Construct validity evidence for measures of depression, hopelessness, and psychache was evaluated with 2974 undergraduates. Analyses indicated three dimensions each contributing to statistically predicting suicide ideation. Contribution patterns supported the differential validity of these dimensions. Whereas hopelessness most strongly contributed to suicide motivation, psychache contributed most strongly to suicide preparation.
\end{abstract}


For North American society, suicide-related behavior is a major public health issue. Suicide is one of the 12 leading causes of death in the United States (National Institute of Mental Health, n.d.) and in Canada (Statistics Canada, 2010). Further, for every death by suicide, there is 50 to 100 times that number of attempted suicides resulting in injuries (Pagliaro, 1995). A risk factor for both death by suicide and attempted death by suicide is suicide ideation (Ranieri, Steer, Lavrence, Rissmiller, Piper, \& Beck, 1987) and, as such, understanding, predicting, and intervening with suicide ideation can have value for the prevention of suicide and attempted suicide.

Prominent risk factors for suicide-related behavior include a previous suicide attempt and biological sex. However, in that historical and many demographic factors are not susceptible to change, recent research has focused on delineating psychological risk variables because such factors are posited to be amenable to therapeutic intervention (Brown, Beck, Steer, \& Grisham, 2000). Particularly salient among the psychological variables related to suicide are the constructs of depression, hopelessness, and psychache (Pereira, Kroner, Holden, \& Flamenbaum, 2010). As a risk factor for suicide, depression has a long history. In his cognitive model, Beck (1967) proposed that the fundamental cause of depression is a triad of dysfunctional negative beliefs about the self, the world, and the future. Empirical data have supported the linkage between depression and suicide (Conwell \& Brent, 1995; McHugh \& Goodell, 1971; Robins, Schmidt, \& O’Neil, 1957; Silver, Bohnert, Beck, \& Marcus, 1971).

Abramson, Metalsky, and Alloy (1989) more finely articulated a cognitive model of depression and suicide that focuses on a subtype of depression, namely hopelessness depression. Hopelessness depression, rather than depression in general, is seen as the relevant precursor to suicide, suicide attempts, and suicide ideation. Research has supported hopelessness as a 
mediator between depression and suicide-related behavior (Dieserud, Roysamb, Ekeberg, \& Kraft, 2001; Dyer \& Kreitman, 1984) and as a predictor of eventual death by suicide (Beck, Brown, Berchick, Stewart, \& Steer, 1990; Beck, Brown, \& Steer, 1989; Beck, Steer, Kovacs, \& Garrison, 1985).

In contrast to cognitive approaches, Shneidman (1993) asserted that suicide is caused by psychache (i.e., intense psychological pain). Psychache is defined as the chronic, free-floating, nonsituation-specific anguish, hurt, angst, humiliation, or, more generally, internal perturbation, that leads individuals to seek permanent escape. The affective state of psychache is distinct from any particular psychiatric diagnosis, and associations between psychological disorders and suicide are mediated by psychache. Thus, psychache is regarded as a necessary condition for suicide. Empirical findings have supported the unique explanatory power of psychache, relative to depression or hopelessness, in the statistical prediction of suicidal manifestations (Berlim et al., 2003; Holden \& McLeod, 2000; Holden, Mehta, Cunningham, \& McLeod, 2001; Pereira et al., 2010; Troister \& Holden, 2010). Psychache was also shown to mediate associations between perfectionism and suicidality (Flamenbaum \& Holden, 2007) and between alexithymia and suicidality (Keefer, Holden, \& Gillis, 2009).

Accumulating evidence has supported the importance of psychache relative to depression and hopelessness for understanding suicidality (DeLisle \& Holden, 2009); however, because scales measuring depression, hopelessness, and psychache have correlated highly, the distinction among these constructs can be challenged (e.g., Shahar, Bareket, Rudd, \& Joiner, 2006). Are depression, hopelessness, and psychache all distinct statistical predictors of suicide manifestations or is any predictive value principally a function of each of these psychological variables assessing a larger, more general expression of negativity? To establish evidence of 
construct validity for depression, hopelessness, and psychache, the current research evaluates whether operationalizations of these constructs assess distinct factors, whether these distinct factors have added value (i.e., incremental validity) in the statistical prediction of suicide ideation, and whether these distinct factors demonstrate differential strengths in statistically predicting different forms of suicide ideation. Based on previous empirical findings (DeLisle \& Holden, 2009; Troister \& Holden, 2010), we hypothesized that

(1) Measures of depression, hopelessness, and psychache would represent three correlated, but distinct, factors. That is, three factors would underlie the latent structure of content scales of depression, hopelessness, and psychache.

(2) The assessment of latent factors for each of depression, hopelessness, and psychache would have added value (i.e., would explain unique variance) in the statistical prediction of suicide ideation. That is, for the simultaneous regression of suicide ideation onto predictors, regression coefficients for factors of depression, hopelessness, and psychache would each demonstrate statistical significance.

Further, based on Shneidman's model of suicide that emphasizes the pre-eminence of psychache as a cause of suicide (Shneidman, 1993) and that other psychological factors are suicide-relevant only to the degree that they produce psychache, we further hypothesized that

(3) Psychache would statistically mediate the associations of depression and hopelessness with suicide ideation. That is, the associations of suicide ideation with depression and hopelessness would decrease significantly when psychache was statistically controlled.

Finally, given the empirical findings that the relevance of internal perturbations was relatively greater for more intense aspects of suicidality (Holden, Kerr, Mendonca, \& Velamoor, 1998), we also hypothesized that 
(4) The prominence of psychache, relative to depression and hopelessness, would be greater for the statistical prediction of the more active or intense, behavioral facets of suicide manifestations. That is, the ratio of regression coefficients of psychache to depression or hopelessness factors would be greater for statistically predicting suicide preparation compared to suicide motivation.

\section{Method}

\section{Participants and Procedure}

This investigation was approved by a University General Research Ethics Board. Participants were 2974 students (2135 women, 769 men, 70 of unreported sex) recruited over two years from introductory psychology course subject pools. The mean age of the sample was 18.31 years $(S D=2.26$; median $=18.00$; range from 16 to 89$)$. Participants were volunteers who completed all materials in single sessions during the first week of the academic term as part of a pre-screening procedure for a university psychology course subject pool.

\section{Measures}

Statistical predictors. Constructs of depression, hopelessness, and psychache were assessed using three self-report scales, with higher scale scores indicating higher scores on the corresponding construct. The Beck Depression Inventory-II (BDI-II; Beck, Steer, \& Brown, 1996) is a 21-item measure of depression symptoms. Items are rated on 4-point scales as applicable within the previous two weeks. Scale alpha reliability coefficients have ranged from .73 to .95 and concurrent validity for the scale has been demonstrated in psychiatric and nonpsychiatric samples (Beck, Steer, \& Garbin, 1988; Spreen \& Straus, 1991). The Beck Hopelessness Scale (BHS; Beck, Weissman, Lester, and Trexler, 1974) is a 20-item, true/false instrument that measures negative expectations about the future. The scale has empirical 
evidence supporting its reliability and validity in clinical and nonclinical samples (Durham, 1982 ) and its ability to predict subsequent death by suicide (Beck et al., 1985, 1989, 1990). The Psychache Scale (Holden et al., 2001) comprises 13 items with content (e.g., "I hurt because I feel empty") that focuses on Shneidman's (1993) definition of psychological pain. Items are answered as 5-point ratings. Scale internal consistency reliabilities have exceeded .90 with samples of undergraduates and prison inmates (Mills, Green, \& Reddon, 2005; Pereira et al., 2010). The Psychache Scale has shown validity by differentiating suicide attempters from nonattempters and by statistically predicting suicidality when controlling for depression and hopelessness (DeLisle \& Holden, 2004, 2009).

Suicidality criteria. The self-report Beck Scale for Suicide Ideation (BSS; Beck \& Steer, 1993) consists of 19 items that assess suicide intent by evaluating the quality and quantity of ongoing suicide ideation. As well as measuring a range of attitudes and behaviors that clinicians regard as relevant for assessing suicidal risk, the BSS assesses specific suicidal characteristics that merit closer clinical focus. Beck and Steer reported BSS alpha reliability coefficients of .87 and .90 , respectively, for outpatient and inpatient suicide ideators. Further, correlations of the BSS with a clinician-rated version were .94 and .90 for outpatients and inpatient samples, respectively (Beck, Steer, \& Ranieri, 1988).

In addition to the total scale, the BSS has two subscales (Beck, Brown, \& Steer, 1997). Whereas the Suicide Motivation subscale assesses a more passive aspect of ideation involving an uncertainty about living or dying in addition to the frequency and duration of suicidal thoughts, the Suicide Preparation subscale involves a more active component, including planning the suicidal act. In a study of suicide attempters, support for the two-factor structure of the scale was found (Holden \& DeLisle, 2005) with further research supporting the internal consistency 
reliability of these subscales (DeLisle \& Holden, 2009). The bi-dimensionality of suicide ideation has also been previously shown (Holden \& Kroner, 2003; Johns \& Holden, 1997) to distinctly relate to dimensions of negative cognitions (for suicide motivation) and action orientation (for suicide preparation). In particular, the action orientation dimension was differentially linked empirically to previous suicide attempts, internal perturbation-based reasons for attempting suicide (Holden \& Kroner, 2003), and self-reported likelihood to die by suicide (Johns \& Holden, 1997). As such, we regarded it as important to separately evaluate the BSS subscales in addition to the total BSS scale.

\section{Results}

For respondents with missing data, scale scores were generated by pro-rating scores provided that no more than $10 \%$ of items within a scale were missing. Within a scale, averaging is appropriate given the small amount of missing data and, particularly, as was present here, when scale internal consistency is high with items forming a single domain (Schafer \& Graham, 2002). Scale descriptive statistics, internal consistency reliabilities, and inter-correlations are presented in Table 1. Descriptive statistics are similar to those reported previously (DeLisle \& Holden, 2009) for university students. Visual inspection of histograms indicated that any distributional non-normality was attributable to skewness and lack of mesokurtosis rather than due to the presence of outliers.

To verify the distinctiveness of the statistical predictors, separately, within each of the BDI-II, BHS, and Psychache scales, item parcels were formed for subsequent factor analyses. Factoring of item parcels is advocated because, relative to individual items, parcels will have greater reliability, higher communality, closer approximations to a normally distributed interval scale, more optimal indicator to sample size ratios, less item-specific anomalous influences, and 
a greater likelihood of an appropriate solution (Meade \& Kroustalis, 2006). We viewed such advantages as important particularly given that the response formats for items differed across the BDI-II, BHS, and Psychache scales. Parcels typically involve three to five items per parcel (Sterba \& MacCallum, 2010) and with a desire to have three or four parcels per scale (Kishton \& Widaman, 1994), we generated parcels comprising either three or four items.

Within a scale, our parceling of items involved principal components analysis of item inter-correlations that evaluated and indicated the presence of a large component (supporting scale unidimensionality) and the allocation of items to parcels such that each parcel had items with approximately equal average loadings on the first unrotated principal component (Meade \& Kroustalis, 2006). This procedure was intended to ensure both unidimensionality and representativeness, characteristics associated with the effective parceling of items (Kishton \& Widaman, 1994), and produced seven item parcels for the BDI-II, six for the BHS, and four for the Psychache scale.

Subsequently, we examined the 17 item parcels with both exploratory and confirmatory analyses. For exploratory analyses, the eigenvalue $>1$ heuristic, a scree plot (Figure 1), and parallel analysis (1,000 replications and 95\% confidence interval) each supported three components. Principal components analysis with either an oblique promax or an orthogonal varimax rotation indicated that the seven BDI-II parcels defined one component, the six BHS parcels defined a distinct component, and the four Psychache parcels defined yet another separate component (Table 2). Using a confirmatory approach, maximum likelihood factor analysis of the 17 item parcels supported the model that depression, hopelessness, and psychache were three distinct constructs (Figure 2$), \chi^{2}(113)=389.58, p<.01, \mathrm{NFI}=.994, \mathrm{CFI}=.996$, GFI $=.999, \mathrm{AGFI}=.999, \mathrm{RMSEA}=0.032(90 \%[\mathrm{CI}]=.029, .036)$. Further, this model had 
significantly better fit than a one-factor model, $\Delta \chi^{2}(6)=10177.90, p<.01$. Thus, in support of our first hypothesis, both exploratory and confirmatory analyses indicated the differentiation of measures of depression, hopelessness, and psychache into three corresponding separate factors.

Next, separately for each of the total BSS scale and its subscales of Suicide Motivation and Suicide Preparation, scores were linearly regressed simultaneously on to promax-rotated maximum likelihood factor scores for the three factors of depression, hopelessness, and psychache (Table 3). In support of our second hypothesis, for every regression, depression, hopelessness, and psychache each contributed significantly to each statistical prediction.

Shneidman's (1993) causal model of suicide would predict that other psychological factors are only relevant to suicide because of their associations with psychache. Therefore, psychache should mediate the associations between other psychological variables (i.e., depression, hopelessness) and suicide criteria. As such, we evaluated the potential mediating effects of the psychache factor on the associations of factors of depression and hopelessness with suicide ideation through the SPSS MEDIATE procedure of Hayes and Preacher (2011) and using 95\% confidence intervals with 10000 bootstrap samples. Although for each of the total BSS scale and its subscales, the psychache factor significantly mediated the links from each of depression and hopelessness factors, alternative mediation models were also tested and similarly supported. That is, for every outcome measure of suicide ideation, each predictor (i.e., depression, hopelessness, psychache) significantly mediated the associations between every other predictor and suicide ideation. In all instances, significant partial, but not full, mediation was present. ${ }^{1}$ This result does not fully support our third hypothesis derived from Shneidman's assertion that all other psychological factors are only relevant for suicide to the extent that they relate to psychache. 
To more fully articulate the relative merits of depression, hopelessness, and psychache in the statistical prediction of suicide ideation, we evaluated the equality of coefficients within a regression equation using procedures detailed by Kenny $\left(1979\right.$, p. 69) to compare the $R^{2}$ of an equation containing separate predictors versus summed predictors. If the standardized regression weights for two predictors are equal, the increase in $R^{2}$ between estimating a common weight for the predictors and computing distinct coefficients for the predictors should be nonsignificant. In predicting the total BSS, the regression coefficient for the depression factor was significantly less than for factors of hopelessness, $F(1,2177)=5.16, p<.05$, or psychache, $F(1,2177)=6.75, p$ $<.01$, which did not differ significantly, $F(1,2177)=0.26, p>.05$. For predicting Suicide Motivation, the regression coefficient for the hopelessness factor was significantly greater than for depression, $F(1,2274)=13.48, p<.01$, or psychache, $F(1,2274)=4.56, p<.05$, which did not differ significantly, $F(1,2274)=2.95, p>.05$. In predicting Suicide Preparation, the regression coefficient for the psychache factor surpassed that for either depression, $F(1,2172)=$ $10.59, p<.01$, or hopelessness, $F(1,2174)=4.11, p<.05$, which did not differ significantly, $F$ $(1,2172)=2.68, p>.05$. Interpretations, similar to those based on standardized regression weights, of the relative size of contributions to predicting suicidality criteria emerged (Table 3) when based on general dominance weights or relative importance weights (Braun \& Oswald, 2011; Tonidandel, LeBreton, \& Johnson, 2009). Thus, in support of our fourth hypothesis, whereas psychache had a less prominent role than hopelessnesss in the statistical prediction of suicide motivation, psychache was the most important contributor to the statistical prediction of the more intense, behavioral aspect of suicide ideation, suicide preparation.

Discussion 
As a primary cause of death globally, suicide annually accounts for nearly one million fatalities worldwide (World Health Organization, 2000). Although identifying individuals at risk for suicide is an important aim for practitioners and researchers, another essential health goal is specifying malleable antecedents that subsequently result in suicidal behavior. Toward that end, mental health research has focused on suicide-related constructs such as depression, hopelessness, and psychache. Although each of these psychological variables has been associated empirically with suicidal behavior, the relationships among the constructs have not been fully articulated. The present research contributes by establishing the extent of independence of these psychological variables, by evaluating their added value (i.e., their contribution to prediction independent of other predictors) for statistically predicting suiciderelated behavior, and by supporting the construct validity of these psychological variables through demonstrating their differential relevance for statistically predicting separate suicide criteria that vary in degree of intensity.

First, in examining the latent structure for parcels of depression, hopelessness, and psychache items, favored heuristics for determining the number of factors to retain all uniformly indicated three factors. Further, exploratory analyses using item parcels resulted in a perfect sorting of parcels, in terms of salience, into corresponding dimensions of depression, psychache, and hopelessness, regardless of whether oblique or less appropriate orthogonal (i.e., varimax) rotations were used. In addition, confirmatory analyses with item parcels hypothesized to load on three corresponding factors, demonstrated excellent fit and a substantially better fit than for a one-factor model. In the three-factor confirmatory model, factors did correlate .54 to .69 but, nevertheless, their differentiation was empirically indicated. Thus, rather than one general factor 
of negativity, evidence supported the delineation of variables into three correlated, but distinct, dimensions with each one defined by items predominantly from a single scale.

Second, although three factors were indicated, these factors could possibly reflect response styles rather than content dimensions. Consider that the number of response options per item is four, two, and five for the BDI-II, BHS, and Psychache items, respectively, and could potentially be the basis for factor differentiation. The interpretation and utility of factors cannot be determined solely by their factor space prominence but must be established through their differential validity in predicting meaningful criterion variables (Jackson, Paunonen, Fraboni, \& Goffin, 1996). Thus, it is essential to demonstrate that these factors have added value (i.e., make unique statistically significant contributions) in predicting a relevant criterion. As such, the significance of each of the factor score coefficients in each of the multiple regressions provides confirmatory evidence that legitimizes the content, rather than stylistic, interpretation of the obtained factors.

Third, evidence for the construct validity of emerged factors is enhanced further by their differential prominence in statistically predicting different relevant criteria. If extracted factors represented the same underlying construct, different patterns of regression weights should not emerge. Yet, whereas for the statistical prediction of suicide motivation, the hopelessness factor had a regression weight significantly greater than the other variables, the psychache factor was significantly more prominent than the other variables for the statistical prediction of suicide preparation. The pattern of differential validity supports both the separate content interpretation and construct validity of these latent variables.

Present results both support and also challenge Shneidman's (1993) model in which psychache is the most proximal, direct cause of suicide and other suicidogenic psychological 
factors are associated with suicide only through psychache. Accordingly, psychache should be regarded as a full mediator of relationships between other psychological variables and suicide. For the current study and supporting Shneidman`s perspective, psychache was significantly correlated with each index of suicide ideation and remained so when statistically controlling for other psychological variables in the multiple regressions. Nevertheless, in challenge to Shneidman`s view, depression and hopelessness factors retained their statistical significance in the multiple regressions when psychache was statistically controlled for.

Although a temporal ordering of cause, mediator, and effect relationships is more properly evaluated through longitudinal research, causal mediation can also be statistically tested within cross-sectional designs, provided that a logical ordering such as in Shneidman's (1993) model is assumed (Preacher \& Hayes, 2008). For a mediator $(M)$ to mediate associations between causal variables $(X \mathrm{~s})$ and an outcome variable $(Y)$, the association between $M$ and $Y$ must be significant, the association between $X \mathrm{~s}$ and $Y$ must be significant, and the association between $X$ s and $Y$ must decrease when $M$ is controlled for (Baron \& Kenny, 1986). Full mediation occurs when the decrease is to zero and partial mediation is indicated by a significant reduction but not to zero. In formally testing for mediation through Hayes and Preacher's (2011) implementation, the psychache factor demonstrated significant partial, but not full mediation, of the associations of depression and hopelessness factors with each of the total BSS, Suicide Motivation, and Suicide Preparation scales. Although the presence of this mediation aligns with Shneidman's (1993) assertion of the importance of psychache, the lack of full mediation is contrary to his claim that all other psychological factors and affective states are only relevant to the extent that they relate to psychache. Furthermore, alternative mediation models were also examined (i.e., depression mediates the association of hopelessness and psychache with suicide 
ideation; hopelessness mediates the association of depression and psychache with suicide ideation) and the occurrence of significant partial, but not full, mediation with almost all of these other models argues against the exclusivity of psychache as a causal agent and also demonstrates the high collinearity among the conceptually and empirically distinct measures of depression, hopelessness, and psychache. Given the cross-sectional nature of the current design and the lack of statistical support for full mediation for psychache, an alternative conceptualization can view depression, hopelessness, and psychache as overlapping risk factors (Kraemer, Stice, Kazdin, Offord, \& Kupfer, 2001) for suicidality that are nonredundant.

A particularly interesting current finding occurred in the multiple regression analyses with an inversion of importance for the statistical predictors as the suicide criterion shifted in intensity. Whereas beta weights (Table 3) for psychache (.21) and hopelessness (.28) yielded a ratio of .75 in statistically predicting suicide motivation, for suicide preparation, the corresponding ratio of 1.63 indicated that the relative importance of psychache more than doubled $(1.63 / .75=2.17)$. A similar inversion for regression weights of hopelessness and internal perturbation-based reasons for attempting suicide (a construct similar to psychache) has been noted previously (Holden et al., 1998) in predicting suicidal desire and suicide preparation for patients attending a psychiatric hospital crisis unit. Johns and Holden (1997) in research with undergraduates and Holden and Kroner (2003) in a study of incarcerated offenders also found that whereas hopelessness tended to cluster with less intense suicide manifestations, internal perturbations-based reasons clustered with more intense suicide actions. Thus, as lethality increases, there emerges a consistent increase in the importance of psychache relative to hopelessness. This increased importance for psychache as the lethality of suicidal manifestations 
intensifies is consistent with Shneidman's (1993) view of the action of suicide as an escape from overwhelming internal psychological pain.

The unique contribution of psychache to understanding suicidality adds a potential treatment avenue beyond currently implemented interventions (e.g., cognitive behavioral therapies, antidepressant medication) that emphasize depressogenic factors. For example, Patterson and Holden (2012) suggested that the importance of psychache may indicate the potential merit of affect-based interventions (e.g., ACT therapy) as an alternative or complement to cognitive-based treatments (e.g., cognitive behavioral therapy). Further, in his psychache causal model of suicide, Shneidman (2005) stated that psychache, itself, results from unfulfilled psychological needs. Thus, tailored anodynic therapy, where anodynic means relieving pain, focusing on an individual's specific frustrated psychological needs can be the means for reducing psychache and, consequently, suicidality. Adapted from Murray's (1938) need theory of personality, Shneidman identified sets of needs that, when frustrated, were especially relevant for suicide; succorance and affiliation; achievement, autonomy, order, and understanding; affiliation, defendence, and shame-avoidance; affiliation and nurturance; dominance and aggression. Following from this, a solutions-focused approach (De Jong \& Berg, 2007) may be utilized to generate concrete ways to fulfill needs that individual clients perceive as not being met. There is also the potential for frustrated psychological needs to be addressed within a cognitive behavioral therapy (CBT) framework. For example, an individual with a frustrated need for affiliation may have the thought "If my friend doesn't want to see me tonight that means she doesn't like me." This thought could be tested and adjusted utilizing CBT techniques such as thought records and behavioral experiments (Greenberger \& Padesky, 1995), which in turn may reduce that individual's level of psychache. Therapeutically addressing these needs when 
thwarted as an intervention for psychache and its subsequent suicidality awaits empirical verification.

Limitations to this research exist. First, this investigation focused on suicide ideation, not death by suicide. Despite being a less than perfect proxy for suicide, suicide ideation is both an antecedent risk factor for suicide as well as a mental health issue in and of itself. Second, participants were predominantly female university undergraduates. Although findings from analogue and clinical samples in depression and attribution research are generally consistent (Vredenburg, Flett, \& Krames, 1993), replication of current results with other populations (e.g., clinical patients, incarcerated offenders) will establish the generalizability of present findings. Third, the current research design was cross-sectional, limiting the ability to draw causal inferences. Are the psychological predictors studied here causes of suicide ideation, does suicide ideation cause depression, hopelessness, and psychache, or does some yet unspecified variable result in changes in suicide ideation, depression, hopelessness and psychache? Longitudinal studies are necessary to determine temporal ordering and the drawing of stronger causal inferences.

In conclusion, in supporting the differentiation of constructs of depression, hopelessness, and psychache, findings of the present research were:

1. Items from scales of depression, hopelessness, and psychache measure three distinct, correlated factors.

2. Factors of depression, hopelessness, and psychache each contribute to statistically predicting suicide ideation. 
3. Collectively, depression, hopelessness, and psychache demonstrate differential patterns of association with suicidality with psychache's relevance becoming more prominent with more lethal aspects of suicide ideation. 


\section{References}

Abramson, L. Y., Metalsky, G. I., \& Alloy, L. B. (1989). Hopelessness depression: A theorybased subtype of depression. Psychological Review, 96, 358-372.

Baron, R. M. \& Kenny, D. A. (1986). The moderator-mediator variable distinction in social psychological research: Conceptual, strategic, and statistical considerations. Journal of Personality and Social Psychology, 51, 1173-1182.

Beck, A. T. (1967). Depression: Causes and treatment. Philadelphia: University of Pennsylvania Press.

Beck, A. T., Brown, G., Berchick, R. J., Stewart, B. L., \& Steer, R. A. (1990). Relationship between hopelessness and ultimate suicide: A replication with psychiatric out patients. American Journal of Psychiatry, 147, 190-195.

Beck, A. T., Brown, G., \& Steer, R. A. (1989). Prediction of eventual suicide in psychiatric inpatients by clinical ratings of hopelessness. Journal of Consulting and Clinical Psychology, 57, 309-310.

Beck, A. T., Brown, G., K., \& Steer, R. A. (1997). Psychometric characteristics of the Scale for Suicide Ideation with psychiatric outpatients. Behaviour Research and Therapy, 35, 10391046.

Beck, A. T., \& Steer, R. A. (1993). Beck Scale for Suicide Ideation manual. San Antonio, TX: Psychological Corporation.

Beck, A. T., Steer, R. A., \& Brown, G. K. (1996). Manual for the Beck Depression Inventory-II. San Antonio, TX: Psychological Corporation. 
Beck, A. T., Steer, R. A., \& Garbin, M. G. (1988). Psychometric properties of the Beck Depression Inventory: Twenty-five years of evaluation. Clinical Psychology Review, 8, 77100.

Beck, A. T., Steer, R. A., Kovacs, M., \& Garrison, B. (1985). Hopelessness and eventual suicide: A 10-year prospective study of patients hospitalized with suicidal ideation. American Journal of Psychiatry, 142, 559-563.

Beck, A. T., Steer, R. A., \& Ranieri, W. F. (1988). Scale for Suicide Ideation: Psychometric properties of a self-report version. Journal of Clinical Psychology, 44, 499-505.

Beck, A. T., Weismann, A., Lester, D., \& Trexler, L. (1974). The measurement of pessimism: The Hopelessness Scale. Journal of Consulting and Clinical Psychology, 42, 861-865.

Berlim, M. T., Mattevi, B. S., Pavanello, D. P., Caldieraro, M. A., Fleck, M. P. A., Wingate, L. R., et al. (2003). Psychache and suicidality in adult mood disordered outpatients in Brazil. Suicide and Life-Threatening Behavior, 33, 242-248.

Braun, M. T., \& Oswald, F. L. (2011). Exploratory regression analysis: A tool for selecting models and determining predictor importance. Behavior Research, 43, 331-339.

Brown, G. K., Beck, A. T., Steer, R. A., \& Grisham, J. R. (2000). Risk factors for suicide in psychiatric outpatients: A 20-year prospective study. Journal of Consulting and Clinical Psychology, 68, 371-377.

Conwell, Y., \& Brent, D. (1995). Suicide and Aging I: Patterns of psychiatric diagnosis. International Psychogeriatrics, 7, 149-164.

De Jong, P., \& Berg, I. K. (2007). Interviewing for solutions (3rd ed.). Belmont, CA: Brooks Cole. 
DeLisle, M. M., \& Holden, R. R. (2004). Depression, hopelessness, and psychache as increasingly specific predictors of suicidal manifestatations. Canadian Clinical Psychologist, 15, 7-10.

DeLisle, M. M., \& Holden, R. R. (2009). Differentiating between depression, hopelessness, and psychache in university undergraduates. Measurement and Evaluation in Counseling and Development, 42, 46-63.

Dieserud, G., Roysamb, E., Ekeberg, O., \& Kraft, P. (2001). Toward an integrative model of suicide attempt: A cognitive psychological approach. Suicide and Life-Threatening Behavior, 31, 153-168.

Durham, T. W. (1982). Norms, reliability, and item analysis of the Hopelessness Scale in general psychiatric, forensic psychiatric, and college populations. Journal of Clinical Psychology, 38, 597-600.

Dyer, J. A. T., \& Kreitman, N. (1984). Hopelessness, depression, and suicidal intent in parasuicide. British Journal of Psychiatry, 144, 127-133.

Flamenbaum, R., \& Holden, R. R. (2007). Psychache as a mediator in the relationship between perfectionism and suicidality. Journal of Counseling Psychology, 54, 51-61.

Greenberger, D., \& Padesky, C. A. (1995). Mind over mood: Change how you feel by changing the way you think. New York: Guilford Press.

Hayes, A. F., \& Preacher, K. J. (2011). Indirect and direct effects of a multicategorical causal agent in statistical mediation analysis. Manuscript submitted for publication.

Holden, R. R., \& DeLisle, M. M. (2005). Factor analysis of the Beck Scale for Suicide Ideation with female suicide attempters. Assessment, 12, 231-238. 
Holden, R. R., Kerr, P. S., Mendonca, J. D., \& Velamoor, V. R. (1998). Are some motives more linked to suicide proneness than others? Journal of Clinical Psychology, 54, 569-576.

Holden, R. R., \& Kroner, D. G. (2003). Differentiating suicidal motivations and manifestations in a forensic sample. Canadian Journal of Behavioural Science, 35, 35-44.

Holden, R. R., \& McLeod, L. D. (2000). The structure of the Reasons for Attempting Suicide Questionnaire (RASQ) in a nonclinical adult population. Personality and Individual Differences, 29, 621-628.

Holden, R. R., Mehta, K., Cunningham, E. J., \& McLeod, L. D. (2001). Development and preliminary validation of a scale of psychache. Canadian Journal of Behavioural Science, $33,224-232$.

Jackson, D. N., Paunonen, S. V., Fraboni, M., \& Goffin, R. D. (1996). A five-factor versus sixfactor model of personality structure. Personality and Individual Differences, 20, 33-45.

Johns, D., \& Holden, R. R. (1997). Differentiating suicidal motivations and manifestations in a nonclinical population. Canadian Journal of Behavioural Science, 29, 266-274.

Keefer, K. V., Holden, R. R., \& Gillis, K. (2009, June). The mediational role of psychache in the relationship between alexithymia and suicidal ideation. Presented at the Canadian Psychological Association Annual Convention, Montreal, Canada.

Kenny, D. A. (1979). Correlation and causality. New York: Wiley.

Kishton, J. M., \& Widaman, K. F. (1994). Unidimensional versus domain representative parceling of questionnaire items: An empirical example. Educational and Psychological Measurement, 54, 757-765. 
Kraemer, H. C., Stice, E., Kazdin, A., Offord, D., \& Kupfer, D. (2001). How do risk factors work together? Mediators, moderators, and independent, overlapping, and proxy risk factors. American Journal of Psychiatry, 158, 848-856.

Meade, A. W., \& Kroustalis, C. M. (2006). Problems with item parceling for confirmatory factor analytic tests of measurement invariance. Organizational Research Methods, 9, 369-403.

McHugh, P. R., \& Goodell, H. (1971). A distinction in the suicidal behavior of patients with sedative poisoning seen in a general hospital. Archives of General Psychiatry, 25, 456-464.

Mills, J. F., Green, K., \& Reddon, J. R. (2005). An evaluation of the Psychache Scale on an offender population. Suicide and Life-Threatening Behavior, 35, 570-580.

Murray, H. (1938). Explorations in personality. New York: Oxford University Press.

National Institute of Mental Health (n.d.). Suicide in the U.S.: Statistics and prevention. Retreived from http://www.nimh.nih.gov/health/publications/suicide-in-the-us-statisticsand-prevention/index.shtml

Pagliaro, L. A. (1995). Adolescent depression and suicide: A review and analysis of the current literature. Canadian Journal of School Psychology, 11, 191-201.

Patterson, A. A., \& Holden, R. R. (2012). Psychache and suicide ideation among men who are homeless: A test of Shneidman's model. Suicide and Life-Threatening Behavior, 42, 147156.

Pereira, E. J., Kroner, D. G., Holden, R. R., \& Flamenbaum, R. (2010). Testing Shneidman’s model of suicidality in incarcerated offenders and in undergraduates. Personality and Individual Differences, 49, 912-917. 
Preacher, K. J., \& Hayes, A. (2008). Asymptotic and resampling strategies for assessing and comparing indirect effects in multiple mediator models. Behavior Research Methods, 40, 879-891.

Ranieri, W. F., Steer, R. A., Lavrence, T. I., Rissmiller, D. J., Piper, G. E., \& Beck, A. T. (1987). Relationships of depression, hopelessness, and dysfunctional attitudes to suicide ideation in psychiatric patients. Psychological Reports, 61, 967-975.

Robins, E., Schmidt, E. H., \& O’Neil, P. (1957). Some interrelations of social factors and clinical diagnosis: A study of 109 patients. American Journal of Psychiatry, 114, 221-231.

Schafer, J. L., \& Graham, J. W. (2002). Missing data: Our view of the state of the art. Psychological Methods, 7, 147-177.

Shahar, G., Bareket, L., Rudd, M. D., \& Joiner, T. E. (2006). In severely suicidal young adults, hopelessness, depressive symptoms, and suicidal ideation constitute a single syndrome. Psychological Medicine, 36, 913-922.

Shneidman, E. S., (1993). Suicide as psychache. Journal of Nervous and Mental Disease, 181, $145-147$.

Shneidman, E. S. (2005). Anodyne psychotherapy for suicide: A psychological view of suicide. Clinical Neuropsychiatry, 2, 7-12.

Silver, M., Bohnert, M., Beck, A. T., \& Marcus, D. (1971). Relation of depression to attempted suicide and seriousness of intent. Archives of General Psychiatry, 25, 573-576.

Spreen, O., \& Strauss, E. (1991). A compendium of neuropsychological tests: Administration, norms, and commentary. Oxford, UK: Oxford University Press.

Statistics Canada (2010). Leading causes of deaths in Canada, 2007. Ottawa: Government of Canada. 
Sterba, S. K., \& MacCallum, R. C. (2010). Variability in parameter estimates and model fit across repeated allocations of items to parcels. Multivariate Behavioral Research, 45, 322358.

Tonidandel, S., LeBreton, J. M., \& Johnson, J. W. (2009). Determining the statistical significance of relative weights. Psychological Methods, 14, 387-399.

Troister, T., \& Holden, R. R. (2010). Comparing psychache, depression, and hopelessness in their associations with suicidality: A test of Shneidman's theory of suicide. Personality and Individual Differences, 49, 689-693.

Vredenburg, K., Flett, G. L., \& Krames, L. (1993). Analogue versus clinical depression: A critical reappraisal. Psychological Bulletin, 113, 327-344.

World Health Organization (2000). Preventing suicide: A resource for general physicians. World Health Organization. 


\section{Footnote}

${ }^{1}$ The lack of full mediation is also indicated by the presence of significant regression weights for each predictor in the simultaneous regressions (Table 3). 
Table 1

Scale Intercorrelations, Coefficient Alpha Reliabilities, Means, and Standard Deviations

\begin{tabular}{ccccccc}
\hline & & & & & \\
Scale & 1 & 2 & 3 & 4 & 5 & 6 \\
\hline
\end{tabular}

\section{$\underline{\text { Psychological Statistical Predictor }}$}

1. Beck Depression Inventory

.89

2. Beck Hopelessness Scale

.51

.80

3. Psychache Scale

.64

.49

.94

$\underline{\text { Suicide Criterion }}$

4. Beck Scale for Suicide Ideation

.46

.46

.52

.78

5. Suicide Motivation

.44

.47

.48

.86

.73

6. Suicide Preparation

.36

.35

.44

.90

.63 
$S D$

Skewness

Note. Coefficient alpha reliabilities are in the diagonal. All values for skewness and kurtosis indicate significant non-normality. 
Table 2

Principal Component Loadings for Item Parcels

Promax-Rotated Pattern Matrix

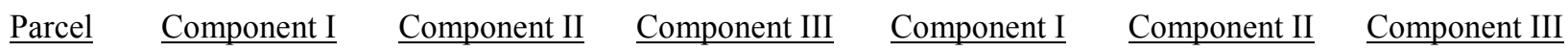

D1

.63

.00

D2

D3

D4

D5

D6

D7

H1

$\mathrm{H} 2$

H3

H4

H5

H6

P1

P2
.00

.74

.79

.72

.66

.74

.70

$-.03$

$-.05$

$-.01$

$-.01$

.00

.09

$-.05$

.91

.93
.15

$-.02$

$-.08$

$-.04$

$-.02$

.07

.01

.65

.69

.71

.60

.51

.62

.02

.01
.67

.22

.73

.76

.72

.68

.73

.71

.13

.13

.19

.14

.22

.20

.31

.86

.33

.86
.31

.17

.11

.15

.17

.25

.19

.70

.71

.72

.67

.60

.68

.22

.22 


$\begin{array}{lllllll}\text { P3 } & .05 & \mathbf{. 8 4} & -.02 & .32 & \mathbf{. 8 3} & .18 \\ & & & & & & \\ \text { P4 } & .03 & \mathbf{8 7} & .00 & .32 & \mathbf{. 8 4} & .20\end{array}$

Note. Parcels D1 to D7, H1 to H6, and P1 to P4 refer to parcels of BDI-II, BHS, and Psychache Scale items, respectively. Loadings $>.35$ in bold. For the promax-rotated solution, Components I and II, I and III, and II and III correlate .67, .58, and .52, respectively. 
Table 3

Standardized Regression Coefficients (General Dominance Weights, Relative Importance Weights) for Statistically Predicting Suicide Criteria from Promax-Rotated Factor Scores

\section{$\underline{\text { Suicide Criterion }}$}

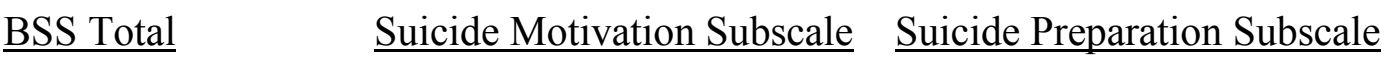

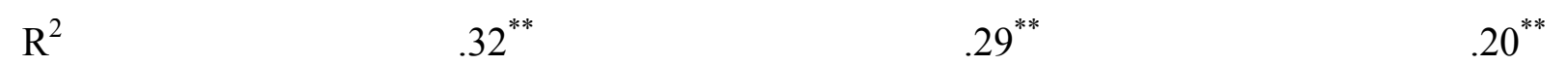

$\underline{\text { Predictor }}$

$\begin{array}{llll}\text { Depression Factor } & .14^{* * \mathrm{~B}}(.10, .09) & .13^{* * \mathrm{~B}}(.09, .08) & .09^{* * \mathrm{~B}}(.06, .06) \\ \text { Hopelessness Factor } & .23^{* * \mathrm{~A}}(.10, .11) & .28^{* * \mathrm{~A}}(.12, .12) & .16^{* * \mathrm{~B}}(.06, .06) \\ \text { Psychache Factor } & .27^{* * \mathrm{~A}}(.12, .12) & .21^{* * \mathrm{~B}}(.09, .10) & .26^{* * \mathrm{~A}}(.09, .09)\end{array}$

${ }^{* *} p<.01$. 
Note. General dominance weights and relative importance weights, respectively, are in parentheses after standardized regression coefficients. To address issues of data non-normality, the statistical significance of regression coefficients was confirmed through bootstrapping (1000 resamples). Within a suicide criterion, standardized regression coefficients with a common superscript do not differ significantly, based on statistical testing procedures outlined by Kenny (1979, p. 69). 
Figure 1.

Scree Plot for Item Parcel Components

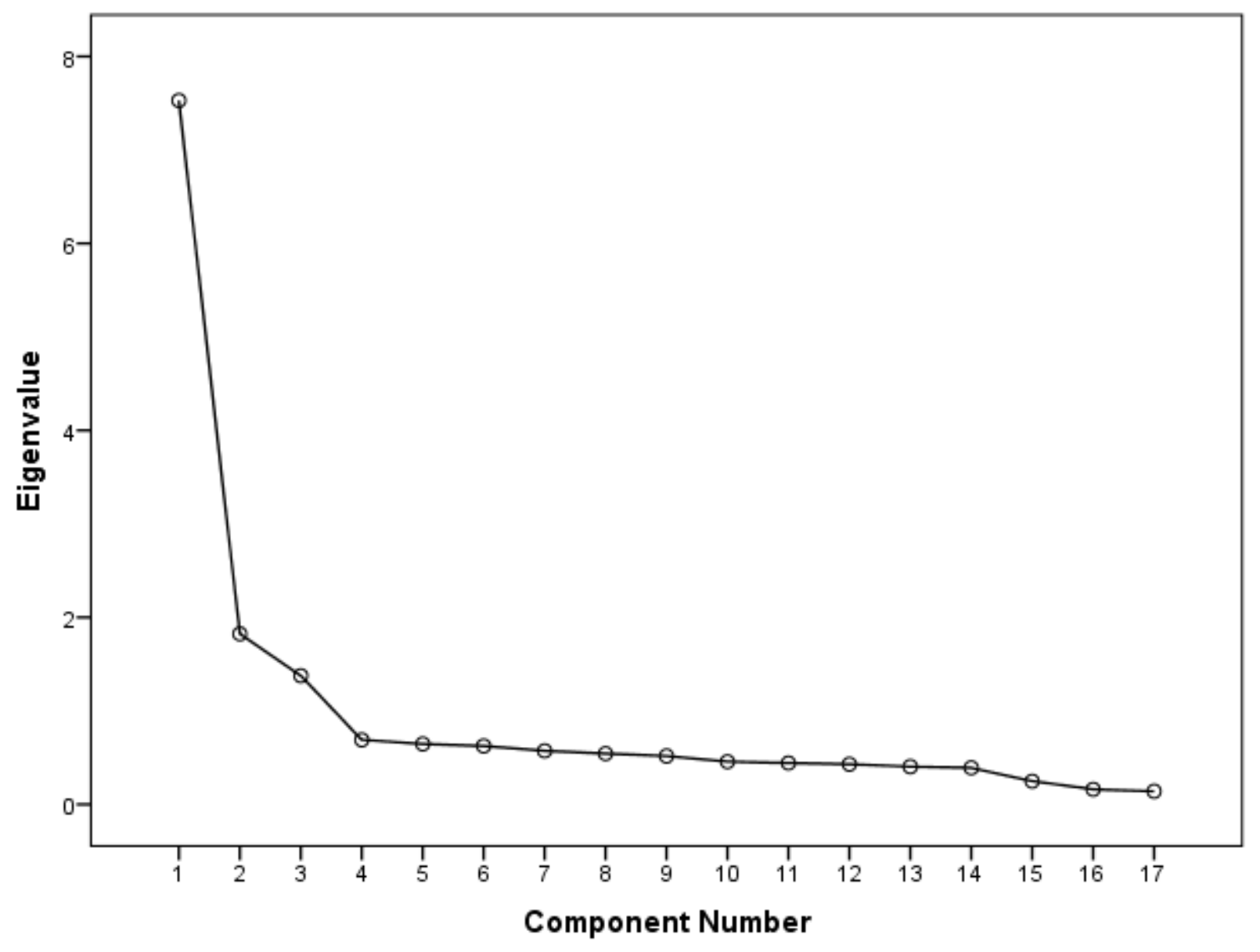


Figure 2.

Confirmatory Factor Analysis (Standardized Solution)

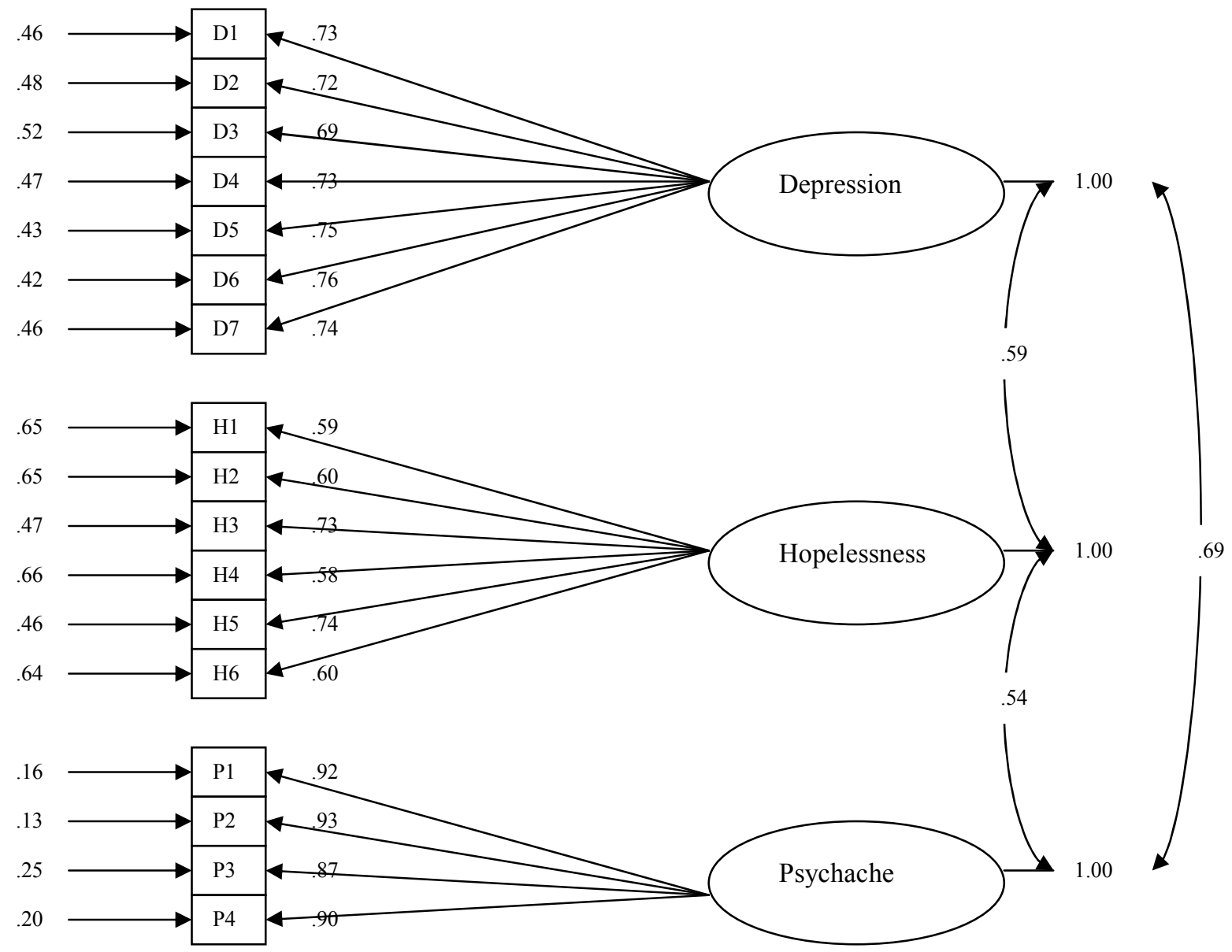

Note. D1 to D7, H1 to H6, and P1 to P4 refer to parcels of BDI-II, BHS, and Psychache Scale items, respectively. 
CHAPTER 3:

A TWO-YEAR PROSPECTIVE STUDY OF PSYCHACHE AND ITS RELATIONSHIP TO SUICIDALITY AMONG HIGH-RISK UNDERGRADUATES 


\begin{abstract}
Edwin Shneidman's theory of suicide was tested by examining the relationships of depression, hopelessness, and psychache with suicide ideation, longitudinally. Forty-one high-risk students who were suicide ideators completed questionnaires measuring depression, hopelessness, psychache, and suicide ideation at baseline and two years later. Regression analyses showed that at baseline and at follow-up, psychache was the only unique contributor to the statistical prediction of suicide ideation. When examining change over time, change in psychache was the only factor that added significant unique variance to the prediction of change in suicide ideation. Results support Shneidman's assertion that other psychological factors, such as depression and hopelessness, are only important to suicide insofar as their relationship with psychache, and that psychache and suicide ideation co-vary over time.
\end{abstract}


Worldwide, suicide claims the lives of almost one million people per year (World Health Organization, 2002). In the United States, approximately 85 individuals die by suicide every day (Moscicki, 1999), and suicide is the $10^{\text {th }}$ leading cause of death in each of the U.S. (National Institute of Mental Health, n.d.), and Canada (Statistics Canada, 2007). Furthermore, it is estimated that for every death by suicide there are approximately 18 suicide attempts (Moscicki, 1997). Identifying potential psychological causes of suicide, and suicide-related behaviors, is an important endeavour because mental health issues can be better addressed and treated through prevention and intervention programs than can non-psychological risk factors (e.g., sex, suicide attempt history). Three prominent psychological factors, depression, hopelessness, and psychache, have been implicated as related to suicidal events.

Early research on psychological predictors identified depression as highly associated with suicidal outcomes (Robins, Schmidt, \& O’Neil, 1959). Beck (1963) theorized that depression is caused by an individual having negative thoughts about himself/herself, the world, and the future. A large body of research supports the link between depression and suicidal manifestations (Bradvick, Mattisson, Bogren, \& Nettelbladt, 2008; Cheng, Chen, Chen, \& Jenkins, 2000; Yen, Shea, Pagano, Sanislow, Grilo, et al., 2003).

Although past research clearly outlines a role for depression in the prediction of suicide, many depressed individuals are not suicidal and not all suicide attempts occur during a depressive episode (Harkavy-Friedman, Nelson, Venarde, \& Mann, 2004). In investigating the nature of the relationship between depression and suicide, Beck recognized that the cognitive distortions prominent in depressed persons were most relevant to suicidal behavior (Beck, 1963), and believed that affective symptoms were secondary. He noted that "Suicidal preoccupations...seemed related to the patient's conceptualization of his situation as untenable or 
hopeless" (p. 328). Subsequently, the study of hopelessness, or a negative view of the future (Beck), as a cause of suicide flourished, and a substantial amount of research supports a relationship between hopelessness and suicide intent (Lester, Beck, \& Mitchell, 1979; NekandaTrepka, Bishop, \& Blackburn, 1983; Weishaar \& Beck, 1992). A prospective study, following participants for 5 to 10 years, found that a specific cut-off score on a measure of hopelessness at baseline was able to predict $90 \%$ of subsequent deaths by suicide in a group of inpatients (Beck, Brown, \& Steer, 1989). Therefore, it is clear that both depression and hopelessness are relevant factors in the prediction of suicidal outcomes.

Although both depression and hopelessness have received abundant support as psychological predictors of suicidality (Lester, Beck, \& Mitchell, 1979; Thompson, Mazza, Herting, Randell, \& Eggert, 2005), neither variable alone, or in combination, is able to account fully for suicidality. In more recent years, Edwin Shneidman, a prominent researcher in the area of suicidology, proposed that psychological pain, or psychache, is necessary and sufficient for suicide to occur (Shneidman, 1993). Psychache is defined as the "hurt, anguish, soreness, aching, psychological pain in the psyche, the mind" (Shneidman, 1993, p. 145) that causes an individual to seek escape through suicide when the pain becomes unbearable. He argued that other established predictors of suicide, such as depression and hopelessness, are secondary and only relevant insofar as their association with psychache.

Initial support for psychache as a factor in suicide is strong. Psychache has been shown to be a significant predictor of suicide ideation in university students (Flynn \& Holden, 2007; Holden et al., 2001; Troister \& Holden, 2010), and correlated with suicide attempter status in a group of offenders (Mills, Green, \& Reddon, 2005). In a group of offenders and university students, psychache was more important than either depression or hopelessness as a statistical 
predictor of suicidality (Pereira, Kroner, Holden, \& Flamenbaum, 2010). Research has also supported Shneidman's assertion that the relationship of other factors with suicide is mediated by psychache. DeLisle and Holden (2009) found good fit for a model in which psychache mediated the effects of hopelessness and depression, and was the most proximal factor associated with suicidality. Psychache has also been shown to fully mediate the relationship between perfectionism and suicidality (Flamenbaum \& Holden, 2007) and between alexithymia and suicidality (Keefer, Holden, \& Gillis, 2009).

Current literature supports the importance of psychache in its relationship to suicidality and that it merits consideration alongside depression and hopelessness as a psychological predictor and potential cause of suicide. At present, however, all published research on psychache has been cross-sectional. Therefore, although it is clear that psychache is strongly related to suicidality, it is unclear if psychache is a cause of, a consequence of, or merely related to suicidal manifestations and behaviors. Prospective designs are needed in order to make stronger inferences concerning causality.

A further limitation of past psychache research is the focus on relatively healthy populations as opposed to individuals at high risk for suicide-related behaviors. Individuals who have attempted suicide in the past or are reporting current suicide ideation represent a particularly relevant group to examine prospectively. It is well established in the literature that a history of suicidality, including attempts, self-harm, and ideation, is predictive of future suicide attempts (Joiner et al., 2005; King et al., 2001), putting these individuals at relatively heightened risk for suicide-related behaviors.

Therefore, the purpose of the current study was to examine psychache longitudinally for a group of relatively at-risk university students. This design will allow further inferences to be 
drawn on the causal implications of these psychological variables for suicidality, as well as the generalizability of results to clinical/high-risk samples. Based on Shneidman's model of suicide, the following hypotheses were evaluated:

1. Psychache would correlate significantly with measures of suicidality.

2. In the statistical prediction of suicidality, psychache would be more important than either depression or hopelessness, and reduce their contributions to suicide ideation to nonsignificant levels at baseline and follow-up.

3. Change in psychache will be more important than change in depression and hopelessness- and reduce their contribution to nonsignificant levels- when examining change in suicide ideation over the two-year period.

Method

\section{Participants}

Forty-one participants, who were designated as high-risk at baseline, completed materials again at two-year follow-up. Participants ranged in age from 17 to 22 years $(M=17.95, S D=$ .95 ) and $83 \%$ were women. All individuals were treated in accordance with guidelines of the University Research Ethics Board.

The sample was obtained from an introductory psychology participant subject pool. A high-risk sample was obtained from this larger pool based on two criteria. Participants were contacted two years later for follow-up if they, a) at baseline, endorsed having a history of at least one suicide attempt, or b) if they were considered suicide ideators at baseline, based on endorsing items indicating active or passive suicidal desire. This method of identifying suicide ideators is described by Beck and Steer (1991) and means that anyone with a score greater than zero on either item four or five was included in the high-risk group. 


\section{Procedure}

At baseline, participants were asked to provide their age and gender, to indicate whether they had ever attempted suicide and, if so, how long ago their most recent attempt was, how they attempted to commit suicide, how intent they were on killing themselves during their most recent attempt, and how many times they had attempted suicide in their lifetime. In addition, individuals were asked to complete measures of suicide ideation, psychache, depression, and hopelessness.

Eligible participants, based on the above two criteria, were contacted via email to participate two years later and were asked to complete the same materials in an online format. At this time, they were offered $\$ 10$ as compensation for their participation. Of the individuals who participated at baseline, 161 were contacted to participate at follow-up, and of those contacted, 41 individuals participated at two year follow-up. There were no significant differences between those who did and not participate on any of the variables of interest at baseline.

\section{Measures}

\section{Statistical Predictors}

The Psychache Scale (Holden et al., 2001) is a 13-item self-report scale used to assess Shneidman's (1993) conceptualization of psychache or psychological pain (e.g., "I hurt because I feel empty"). Alpha reliability coefficients above .90 have been reported in both university (Troister \& Holden, 2010) and offender populations (Mills et al., 2005). The Psychache Scale has also been shown to distinguish between suicide attempters and nonattempters (Holden et al.).

The Beck Depression Inventory (BDI-II; Beck, Steer, \& Brown, 1996) is a 21-item scale that measures depression severity by asking participants to rate each item on a 4-point scale according to their experiences over the past two weeks. The scale has been shown to have high 
internal consistency in psychiatric outpatients (Beck, Steer, Ball, \&, Ranieri, 1996), as well as convergent and discriminant validity with psychiatric inpatients (Osman et al., 2004).

The Beck Hopelessness Scale (BHS; Beck et al., 1974) is a 20-item true/false measure used to assess negative expectations for the future. The scale alpha reliability in a group of patients hospitalized for a suicide attempt was .93 . The BHS has also been shown to have high test-retest reliability (Holden \& Fekken, 1988), and is able to predict subsequent death by suicide (Beck, Brown, \& Steer, 1989).

Suicidality Criterion

The Beck Scale for Suicide Ideation (BSS; Beck \& Steer, 1991) is a 19-item measure of suicide ideation and intent. For the BSS, alpha reliability coefficients have ranged from .84 to .93 in psychiatric samples (Beck, Brown, \& Steer, 1997; Beck, Kovacs, \& Weissman, 1979; Beck, Steer, \& Ranieri, 1988).

\section{Results}

Of the 41 participants, 16 reported a previous suicide attempt when asked at baseline. The most common method used was pills $(31.3 \%)$, followed by cutting $(25 \%)$. Suicide attempters reported a mean of 28.50 months since their most recent suicide attempt $(S D=21.95$, range $=2$ to 72), and a moderate to high level of suicide intent at the time of that attempt $(M=3.39, S D=$ 1.04) on a five-point rating scale. Their number of lifetime attempts ranged from 1-3 ( $M=1.64$, $S D=.75)$. Descriptive statistics for baseline and follow-up are reported in Table 1. At baseline, the current groups' means and standard deviations for depression, hopelessness, and psychache were similar to those found in other samples of undergraduate students with a suicide attempt history (Flamenbaum \& Holden, 2007; Munchua, 2003). Mean total scores for suicide ideation were much lower than those found in inpatient attempters, and slightly lower than outpatient 
attempters (Beck \& Steer, 1991). Means were more similar, albeit slightly lower, than those found in other studies examining university students with a suicide attempt history (DeLisle \& Holden, 2005; Flamenbaum \& Holden). Lower scores on this scale are appropriate as the current sample included a large percentage of individuals who would be considered suicide ideators, but who had not made a previous attempt. One would expect lower means for ideators because of many items that pertain to actions that are more likely to have been undertaken by someone who has made a suicide attempt (i.e., "Have you ever made any preparation for any attempt to end your life?"). Over the two-year period there were significant changes in levels of depression, psychache, total suicide ideation, such that participants had less suicide ideation at two-year follow-up and lower levels of depression and psychache. Levels of hopelessness did not change significantly over the two-year period.

Correlations between predictor and criterion variables for baseline and two-year followup are reported in Table 2. Significant, positive correlations were obtained between the psychological variables of depression, hopelessness, and psychache at each time. The correlations among the predictor variables are comparable to those found in other research with university students (DeLisle \& Holden, 2009). At baseline and follow-up, significant, positive correlations were also found between the three predictor variables and the criterion of suicidal ideation. In terms of magnitude, at two-year follow-up, suicide ideation was most strongly correlated with psychache, as compared to its correlations with depression and hopelessness.

To assess the relative importance of each predictor, the suicide ideation criterion was regressed simultaneously on to the psychological predictors (Table 3) at baseline and at two-year follow-up, and statistically significant standardized regression weights were compared. Due to violations of distributional normality, nonparametric bootstrapping with 5000 bootstrap samples 
was used to evaluate statistical significance. At both baseline and at two-year follow-up, the three predictors collectively were able to significantly predict the BSS total score. When looking at the individual predictors, only psychache contributed significant unique variance to the prediction of suicide ideation at baseline and at two-year follow-up. These results confirm the importance of psychache as a predictor of suicide ideation, supporting the second hypothesis in that depression and hopelessness were not statistically significant when levels of psychache were controlled.

To assess whether a change in suicide ideation over time can be accounted for by changes in depression, hopelessness, and psychache, change scores were calculated for the four variables of interest. Although earlier research cautions against the use of change scores (Cronbach \& Furby, 1970), more recent work has outlined situations where the use of change scores is legitimate and preferred to other analyses (Maxwell \& Howard, 1981; Zumbo, 1999). Change scores were calculated by subtracting baseline scores on the variables from scores at follow-up. Therefore, positive change scores were indicative of a rise in levels of the variable. For each participant a change score was calculated for depression, hopelessness, psychache, and total suicide ideation. The results of the regression analysis using changes scores are also reported in Table 3. Again, due to nonnormality of the data, bootstrapping was used to construct confidence intervals around regression coefficients using 5000 resamples to test for significance. Results indicate that the overall regression model for the change over two years was significant. Once again, only change in psychache contributed unique explanatory variance, supporting the notion that it is an important predictor of change in suicide ideation. This finding supports the third hypothesis as changes in depression and hopelessness were not statistically significant when changes in psychache were controlled. 
Analyses were also run at a later time with 98 participants. Due to the larger sample size, a regression analysis could be run without the use of change scores. In this case, follow-up ideation scores were regressed on follow-up scores on psychache while covarying follow-up scores on depression and hopelessness, and all corresponding baseline scores. Results were identical to change score analyses as baseline suicide ideation and follow-up psychache scores were the only significant predictors of follow-up suicide ideation scores. These results are reported in Appendix A.

To more finely articulate the relative importance for regression predictors that are highly correlated (as in this study), procedures recommended for addressing multicollinearity (Braun \& Oswald, 2011; Tonidandel \& LeBreton, 2011) calculated general dominance weights and relative importance weights. Dominance weights for a regression sum to the overall model $R^{2}$ and are the average squared semipartial correlation for a predictor across all possible subset regressions. For relative importance weights, where a set of predictors has been transformed into a new set of orthogonal predictors that maximally correlate with the original set, a relative importance weight is the regression weight squared for a given predictor regressed on its orthogonal counterpart, multiplied by the regression weight squared of the criterion on that given predictor's orthogonal counterpart. Calculated dominance and corresponding relative importance weights (Table 4) were almost identical and for no model was a weight for psychache exceeded by another predictor. For baseline suicide ideation, weights for depression and psychache were comparable and more than double the values for hopelessness. For two-year follow-up suicide ideation and change in suicide ideation, weights for psychache surpassed those for depression and hopelessness by a factor of 1.5 .

Discussion 
The present study is the first to examine psychache and its relationship to suicide ideation in a longitudinal fashion, for a relatively high-risk group. The issue of whether change in psychache is a better predictor of change in suicide ideation than either change in depression or hopelessness was addressed. Results showed that when examining these variables over a twoyear period, change in psychache was the only variable that contributed significant, unique explanatory variance to the prediction of change in suicide ideation. This is the first time that this relationship has been established between psychache and suicide ideation over a two-year period, and indicates that the two variables do change together over time.

The current study also addressed Shneidman's claim that other predictors are only relevant to suicide ideation in terms of their association with psychache. His assertion was supported in that statistically controlling for psychache reduced the contributions of depression and hopelessness to nonsignificant levels in all three regression analyses. This finding is consistent with findings from other university students (DeLisle \& Holden, 2009), offenders (Pereira et al., 2010), and community samples (Holden et al., 2001). The strengths of assessing psychache were further statistically demonstrated through comparisons of dominance and relative importance weights where the contributions of psychache to explaining variance in suicide ideation exceeded those of either depression or hopelessness.

These findings suggest that psychache merits consideration alongside depression and hopelessness as a pre-eminent factor that should be taken into account when determining suicide risk. Although strong causal inferences are limited in non-experimental designs, current findings do provide a stronger basis for making such causal inferences when compared to previous crosssectional work. As one of the requirements for causal interpretation, the demonstration of concomitant variation between cause and effect requires both an association between two 
variables and an association between the changes of two variables. Thus, the present findings of associative variation in change scores between suicide ideation and psychache when controlling for change in each of depression and hopelessness provides a more stringent test of possible causality.

\section{Limitations and Future Research}

This research has potential limitations based on the obtained sample, the materials used, and the research design. This sample was drawn from a group of undergraduate students and the sample is predominantly female, with little age variability. Participants do represent a relatively high-risk group of students, but they are still comparatively healthy relative to samples of offenders and/or inpatients. Although past research has found consistency in depression research between analogue and clinical samples (Vredenburg, Flett, \& Krames, 1993), further study on more diverse clinical samples is required to confirm the generalizability of these results.

The generalizability of current findings to the prediction of actual attempted suicide and death by suicide also needs to be verified. The current research used suicide ideation as a proxy for more serious suicidal outcomes. Past research confirms that a history of suicidality is the best predictor of later suicidal behaviors (Joiner et al., 2005); however, not everyone who dies by suicide has made a previous attempt. Although the suicide criterion used in this study is not a perfect proxy for attempted suicide or death by suicide, serious thoughts of killing oneself, and actions towards an attempt, are serious mental health concerns that, in of itself, warrants research attention.

The consideration of potential limitations can help guide plans for future research. The current study is the first to examine psychache in a group of suicide ideators and attempters in a prospective manner. A prospective design is a preliminary step to understanding the links 
between psychache, hopelessness, and depression over time, and how they may cause suicidal outcomes. To further establish psychache as a causal factor of suicidal outcomes, research with larger sample sizes will permit more powerful alternative analysis techniques to be employed. In addition, this type of research is mandated for other high-risk suicidal groups such as psychiatric inpatients and/or offenders. To date, there has been some cross-sectional research examining psychological pain in suicide attempters (Flynn \& Holden, 2007), and in mood-disordered outpatients (Berlim et al., 2003), but additional research with other at-risk groups and with a longitudinal component is required to understand more fully the psychological causes of suicidality.

\section{Conclusions}

This study contributes to the field of suicidology by finding that in a group of high-risk university students, psychache is a unique predictor of suicide ideation, and the consideration of psychache reduced the contributions of depression and hopelessness to nonsignificant levels. This result was found at both baseline and at two year follow-up, as well as when evaluating changes in predictor and outcome variables over time. These findings support Shneidman's assertion that other factors are only important to the prediction of suicidality insofar as their relationship to psychache. Given the nature of the research design, we cannot speak definitively regarding causality. However, the result that psychache and suicide ideation have been shown to co-vary over time, while controlling for other predictors, is promising in terms of establishing psychache as a causal factor. The next step for research is to collect additional longitudinal data and to examine other high-risk samples, such as psychiatric inpatients. The present research suggests that the assessment of psychache has merit for the measurement of risk. 


\section{References}

Beck, A. T. (1963). Thinking and depression: I. Idiosyncratic content and cognitive distortions. Archives of General Psychiatry, 9, 324-33.

Beck, A. T., Brown, G. K., \& Steer, R. A. (1997). Psychometric characteristics of the scale for suicide ideation with psychiatric outpatients. Behaviour Research and Therapy, 35, 10391046.

Beck, A. T., Brown, G. K., \& Steer, R. A. (1989). Prediction of eventual suicide in psychiatric inpatients by clinical ratings of hopelessness. Journal of Consulting and Clinical Psychology, 57, 309-310.

Beck, A. T., Kovacs, M., \& Weissman, A. (1979). Assessment of suicide intention: The Scale for Suicide Ideation. Journal of Consulting and Clinical Psychology, 47, 343-352.

Beck, A. T., \& Steer, R. A. (1991). Manual for Beck Scale for Suicide Ideation. San Antonio, TX: Psychological Corporation.

Beck, A. T., Steer, R. A., Ball, R., \& Ranieri, W. F. (1996). Comparison of Beck Depression Inventories-IA and -II in psychiatric outpatients. Journal of Personality Assessment, 67, 588-597.

Beck, A. T., Steer, R. A., \& Brown, G. K. (1996). Manual for the Beck Depression Inventory-II. San Antonio, TX: Psychological Corporation.

Beck, A. T., Steer, R. A., \& Ranieri, W. F. (1988). Scale for Suicide Ideation: Psychometric properties of a self-report version. Journal of Clinical Psychology, 44, 499- 505.

Beck, A. T., Weissman, A., Lester, D., \& Trexler, L. (1974). The measurement of pessimism: The Hopelessness Scale. Journal of Consulting and Clinical Psychology, 42, 861-865. 
Berlim, M. T., Mattevi, B. S., Pavanello, D. P., Caldieraro, M. A., Fleck, M. P. A., Wingate, L. R., \& Joiner, T. E. Jr. (2003). Psychache and suicidality in adult mood disordered outpatients in Brazil. Suicide and Life-Threatening Behavior, 33, 242-248.

Bradvick, L., Mattisson, C., Bogren, M., \& Nettelbladt, P. (2008). Long-term suicide risk of depression in the Lundby cohort 1947-1997-Severity and gender. Acta Psychiatrica Scandinavica, 117, 185-191.

Braun M. T., \& Oswald, F. L. (2011). Exploratory regression analysis: A tool for selecting models and determining predictor importance. Behavior Research Methods.

Cheng, A. T. A., Chen, T. H. H., Chen, C.-C., \& Jenkins, R. (2000). Psychosocial and psychiatric risk factors for suicide: Case-control psychological autopsy. British Journal of Psychiatry, 177, 360-365.

Cronbach, L. J., \& Furby, L. (1970). How should we measure "change"- or should we? Psychological Bulletin, 74, 68-80.

DeLisle, M. M., \& Holden, R. R. (2009). Differentiating between depression, hopelessness, and psychache in university undergraduates. Measurement and Evaluation in Counseling and Development, 42, 46-63.

Flamenbaum, R., \& Holden, R. R. (2007). Psychache as a mediator in the relationship between perfectionism and suicidality. Journal of Counseling Psychology, 54, 51-61.

Flynn, J. J., \& Holden, R. R. (2007). Predictors of suicidality in a sample of suicide attempters. Canadian Psychology, 48:2a, 317.

Harkavy-Friedman, J. M., Nelson, E. A., Venarde, D. F., \& Mann, J. J. (2004). Suicide behavior in schizophrenia and schizoaffective disorder: Examining the role of depression. Suicide and Life-Threatening Behavior, 34, 66-76. 
Holden, R. R., \& DeLisle, M. M. (2005). Factor analysis of the Beck Scale for Suicide Ideation with female suicide attempters. Assessment, 12, 231-238.

Holden, R. R., \& Fekken, G. C. (1988). Test-retest reliability of the Hopelessness Scale and its items in a university population. Journal of Clinical Psychology, 44, 40-43.

Holden, R. R., Mehta, K., Cunningham, E. J., \& McLeod, L. D. (2001). Development and preliminary validation of a scale of psychache. Canadian Journal of Behavioural Science, 33, 224-232.

Joiner, T. E., Jr., Conwell, Y., Fitzpatrick, K. K., Witte, T. K., Schmidt, N. B., Berlim, M. T., Fleck, M. P. A., \& Rudd, M. D. (2005). Four studies on how past and current suicidality relate even when "everything but the kitchen sink" is covaried. Journal of Abnormal Psychology, 114, 291-203.

Keefer, K. V., Holden, R. R., \& Gillis, K. (2009, June). The mediational role of psychache in the relationship between alexithymia and suicidal ideation. Canadian Psychological Association Annual Convention, Montreal, Canada.

King, E. A, Baldwin, D. S., Sinclair, J. M. A., Baker, N. G., Campbell, M., \& Thompson, C. (2001). The Wessex recent in-patient suicide study, 1. Case-control study of 234 recently discharged psychiatric patient suicides. The British Journal of Psychiatry, 178, 531-536.

Lester, D., Beck, A. T., \& Mitchell B. (1979). Extrapolation from attempted suicides to completed suicides: A test. Journal of Abnormal Psychology, 88, 78-80.

Maxwell, S. E., \& Howard, G. S. (1981). Change scores- Necessary anathema? Educational and Psychological Measurement, 41, 747-756.

Mills, J. F., Green, K., \& Reddon, J. R. (2005). An evaluation of the Psychache Scale on an 
offender population. Suicide and Life-Threatening Behavior, 35, 570-580.

Moscicki, E. K. (1997). Identification of suicide risk factors using epidemiological studies. Psychiatric Clinics of North America, 20, 499-517.

Moscicki, E. K. (1999). Epidemiology of suicide. In D. G. Jacobs (Ed.), The Harvard Medical School guide to suicide assessment and intervention (pp. 40-51). San Francisco: JosseyBass.

National Institute of Mental Health (n.d.). Suicide in the U.S.: Statistics and prevention. Retrieved from http://www.nimh.nih.gov/health/publications/suicide-in-the-us-statisticsand-prevention/index.shtml

Nekanda-Trepka, C. J., Bishop, S., \& Blackburn, I. M. (1983). Hopelessness and depression. British Journal of Clinical Psychology, 22, 49-60.

Osman, A., Kopper, B. A., Barrios, F., Gutierrez, P. M., \& Bagge, C. L. (2004). Reliability and validity of the Beck Depression Inventory-II with adolescent psychiatric inpatients. Psychological Assessment, 16, 120-132.

Pereira, E. J., Kroner, D. G., Holden, R. R., \& Flamenbaum, R. (2010). Testing Shneidman’s model of suicidality in incarcerated offenders and in undergraduates. Personality and Individual Differences, 49, 912-917.

Robins, E., Schmidt, E. H., \& O’Neil, P. (1959). Some intercorrelations of social factors and clinical diagnosis in attempted suicide: A study of 109 patients. American Journal of Psychiatry, 114, 221-231.

Shneidman, E. S. (1993). Suicide as psychache. The Journal of Nervous and Mental Disease, 181, 145-147. 
Statistics Canada (2010). Leading causes of deaths in Canada, 2007. Ottawa: Government of Canada.

Steer, R. A., Ball, R., Ranieri, W. F., \& Beck, A. T. (1997). Further evidence for the construct validity of the Beck Depression Inventory-II with psychiatric outpatients. Psychological Reports, 80, 443-446.

Thompson, E. A., Mazza, J. J., Herting, J. R., Randell, B. P., \& Eggert, L. L. (2005). The mediating roles of anxiety, depression, and hopelessness on adolescent suicidal behaviors. Suicide and Life-Threatening Behavior, 35, 14-34.

Tonidandel, S., \& LeBreton, J. M. (2011). Relative importance analysis: A useful supplement to regression analysis. Journal of Business and Psychology, 26, 1-9.

Troister, T., \& Holden, R. R. (2010). Factorial differentiation among depression, hopelessness, and psychache in predicting suicidality. Presented at the American Psychological Association Annual Convention, San Diego.

Vredenburg, K., Flett, G. L., \& Krames, L. (1993). Analogue versus clinical depression: A critical reappraisal. Psychological Bulletin, 113, 327-344.

Weishaar, M. E., \& Beck, A. T. (1992). Hopelessness and suicide. International Review of Psychiatry, 4, 177-184.

World Health Organization (2002). World report on violence and health. Geneva: World Health Organization.

Yen, S., Shea, T., Pagano, M., Sanislow, C. A., Grilo, C. M., McGlashan, T. H., Skodol, A. E., Bender, D. S., Zanarini, M. C., Gunderson, J. G., \& Morey, L. C. (2003). Axis I and Axis II disorders as predictors of prospective suicide attempts: Findings from the 
Collaborative Longitudinal Personality Disorders Study. Journal of Abnormal Psychology, 112, 375-381.

Zumbo, B. D. (1999). The simple difference score as an inherently poor measure of change: Some reality, much mythology. Advances in Social Science Methodology, 5, 269-304. 
Table 1

Means, Standard Deviations, Coefficient Alpha Reliabilities, $t$-tests, and Test-Retest Reliabilities at Baseline and Two Year Follow-Up

\begin{tabular}{|c|c|c|c|c|c|c|c|c|}
\hline & \multicolumn{3}{|c|}{ Baseline } & \multicolumn{3}{|c|}{ Two Year Follow-up } & \multirow[b]{2}{*}{$t(40)$} & \multirow[b]{2}{*}{$\begin{array}{l}\text { Test- } \\
\text { retest }\end{array}$} \\
\hline & $M$ & $S D$ & Alpha & $M$ & $S D$ & Alpha & & \\
\hline \multicolumn{9}{|l|}{ Predictors } \\
\hline Depression & 16.32 & 10.47 & .93 & 11.41 & 10.41 & .93 & $-1.97 * *$ & $.40 * *$ \\
\hline Hopelessness & 5.41 & 3.94 & .82 & 5.82 & 4.45 & .87 & 0.68 & $.53 * *$ \\
\hline Psychache & 28.26 & 13.01 & .97 & 24.46 & 10.45 & .95 & $-2.85 * *$ & $.57 * *$ \\
\hline Criterion & & & & & & & & \\
\hline $\begin{array}{l}\text { Suicide } \\
\text { Ideation }\end{array}$ & 10.25 & 5.70 & .84 & 6.94 & 5.63 & .86 & $-4.57 * * *$ & $.53 * *$ \\
\hline
\end{tabular}

$* * p<.01 ; * * * p<.001$ 
Table 2

Scale Intercorrelations at Baseline and Two Year Follow-Up

\begin{tabular}{lcccc}
\hline Scale & 1 & 2 & 3 & 4 \\
\hline $\begin{array}{l}\text { Psychological Predictor } \\
\text { 1. Depression }\end{array}$ & - & $.81^{* *}$ & $.84^{* *}$ & $.62^{* *}$ \\
2. Hopelessness & $.66^{* *}$ & - & $.79^{* *}$ & $.59^{* *}$ \\
3. Psychache & $.74^{* *}$ & $.72^{* *}$ & - & $.71^{* *}$ \\
$\frac{\text { Suicide Criterion }}{4 . \text { Suicide Ideation }}$ & $.62^{* *}$ & $.47^{* *}$ & $.63^{* *}$ & - \\
\hline
\end{tabular}

Note. Correlations at Baseline are below the diagonal, and Two Year Follow-Up correlations are above the diagonal.

$* * p<.01$. 
Table 3

Standardized Regression Coefficients for Statistically Predicting Suicide Ideation.

\begin{tabular}{|c|c|c|c|c|}
\hline & & \multicolumn{3}{|c|}{ Predictor } \\
\hline & $R^{2}$ & Depression & Hopelessness & Psychache \\
\hline Baseline & $.45 * * *$ & .39 & -.08 & $.39 *$ \\
\hline \multicolumn{5}{|l|}{ Two Year } \\
\hline & $.51 * * *$ & .02 & .07 & $.64^{*}$ \\
\hline \multicolumn{5}{|l|}{ Follow-up } \\
\hline Change $^{\mathrm{a}}$ & $.47 * * *$ & .25 & .20 & $.34 *$ \\
\hline
\end{tabular}

\footnotetext{
${ }^{\mathrm{a}}$ This represents the prediction of change in suicide ideation over two years from changes in the three predictors.

$* p<.05 ; * * * p<.001$.
} 
Table 4

General Dominance Weights and Relative Importance Weights for Statistically Predicting Suicide Ideation.

General Dominance Weight for Predictor

Depression Hopelessness Psychache
Relative Importance Weight for Predictor

\begin{tabular}{|c|c|c|c|c|c|c|}
\hline & \multicolumn{3}{|c|}{ General Dominance Weight for Predictor } & \multicolumn{3}{|c|}{ Relatıve Importance Weight for Predictor } \\
\hline & Depression & Hopelessness & Psychache & Depression & Hopelessness & Psychache \\
\hline Baseline & .19 & .07 & .19 & .19 & .07 & .19 \\
\hline Two Year & & & & & & \\
\hline & .14 & .12 & .25 & .14 & .13 & .25 \\
\hline Change $^{\mathrm{a}}$ & .15 & .14 & .21 & .15 & .14 & .21 \\
\hline Average & .16 & .11 & .21 & .16 & .11 & .21 \\
\hline
\end{tabular}

${ }^{\mathrm{a}}$ This represents the prediction of change in suicide ideation over two years from changes in the three predictors. 
CHAPTER 4:

A FIVE-MONTH LONGITUDNAL STUDY OF PSYCHACHE AND SUICIDE IDEATION: REPLICATION IN GENERAL AND HIGH-RISK UNIVERSITY STUDENTS 


\begin{abstract}
Shneidman's model of psychache as the cause of suicide was evaluated in a 5-month longitudinal study of psychological pain and suicide ideation. Replicating across general $(N=683)$ and highrisk undergraduates $(N=262)$, psychache was significantly associated with suicide ideation, and change in psychache was significantly associated with change in suicide ideation. For general suicide ideation and suicide preparation, these significant results were maintained even when depression and hopelessness were statistically controlled. This research is a unique contribution being the first large-sample longitudinal study that evaluates and supports Shneidman's psychache causal model of suicidality in general and high-risk groups.
\end{abstract}


Suicide is a societal concern and major public health issue. It is one of the 12 leading causes of mortality (National Institute of Mental Health, n.d.; Statistics Canada, 2007) and, worldwide, over one million individuals die by suicide each year (World Health Organization, 2002). As an antecedent to suicide, suicide ideation occurs in about $3 \%$ of the U.S. population (Kessler, Berglund, Borges, Nock, \& Wang, 2005) and is an important mental health issue in itself.

Although primary risk factors for death by suicide include sex and a history of a previous suicide attempt (Moscicki, 1997), a focus on psychological predictors is a favored emphasis because psychological variables may be amenable to therapeutic intervention (Brown, Beck, Steer, \& Grisham, 2000). Psychological factors having particular empirical relevance for suicidal behavior include the constructs of depression (Thomson, 2012), hopelessness (Brown et al., 2000), and psychache (i.e., psychological pain; Troister \& Holden, 2012a).

Psychache is a free-floating, non-situation-specific, chronic hurt, anguish, despair or, more generally, internal perturbation, that causes individuals to seek permanent escape from it (Shneidman, 1993). Shneidman (p. 145) asserted that, "Suicide is caused by psychache" and that all other psychological factors, such as depression, are only important for suicide as they relate to psychache. Death by suicide is not seen as a product of a psychiatric disorder but as an outcome that results from the unbearable psychological pain associated with thwarted psychological needs (Shneidman, 2005). Conceptually, psychache is an affective phenomenon distinct from cognitive states such as depression and hopelessness (Holden, Mehta, Cunningham, \& McLeod, 2001) and multiple exploratory and confirmatory factor analytic studies have substantiated the independent construct validity of measures of psychache (DeLisle \& Holden, 2009; Troister \& Holden, 2013). 
Research has demonstrated significant links between indices of psychache and suicidality (e.g., suicide ideation, suicide motivation, suicide preparation, previous attempts), and the added value of assessing psychache beyond measuring depression and hopelessness (DeLisle \& Holden, 2009; Holden et al., 2001; Mills, Green, \& Reddon, 2005; Troister \& Holden, 2010, 2013). However, to date, investigations of psychache have focused on cross-sectional designs where causal inferences can be tenuous. One two-year longitudinal study (Troister \& Holden, 2012a) showed that change in suicide preparation for high-risk students is predicted by change in psychache independent of changes in depression and hopelessness, however, that study involved a small sample $(N=41)$. Thus, the purpose of the current research is to provide the first largesample longitudinal evaluation of Shneidman's model of psychache as a cause of suicide through a study examining how change in suicidality is uniquely, relative to depression and hopelessness, predicted by change in psychache using samples of both general and high-risk university students.

Demonstrating causality requires that a cause (e.g., psychache) and an effect (e.g., suicide) show concomitant variation, that a cause precedes an effect and, that other causal explanations be ruled out (i.e., principle of ceteris paribus). Experiments with random assignment are the sine qua non for evaluating causality, but quasi-experimental designs can be used to test a priori causal models. Here, we evaluate whether psychache and suicidality are associated and whether this association continues when other suicide-relevant variables of depression and hopelessness are controlled statistically. In addition, we more extensively test concomitant variation by evaluating whether change in the potential cause (i.e., psychache) and change in the effect covary longitudinally and independently of change in alternative potential causes (i.e., depression and hopelessness). Further, we look to demonstrate similarity in findings 
across risk levels in order to support the notion that the psychache model of suicide should be regarded as applicable to all levels of functioning in the general population and, as such, not necessarily linked to a particular psychiatric dysfunction.

Based on Shneidman's theory that psychache causes suicide, we hypothesized that:

1. Psychache would covary with suicide ideation. That is, scores on psychache and suicide ideation scales would correlate significantly.

2. Psychache would covary with suicide ideation controlling for depression and hopelessness. That is, scores on psychache and suicide ideation scales would correlate significantly when scores on depression and hopelessness scales are statistically controlled.

3. Change in psychache would covary with change in suicide ideation. That is, follow-up scores on psychache and suicide ideation scales would correlate significantly when baseline scores on psychache and suicide ideation are statistically covaried out.

4. Change in psychache would covary with change in suicide ideation after controlling for changes in depression and hopelessness. That is, follow-up scores on psychache and suicide ideation scales would continue to correlate significantly when follow-up scores on depression and hopelessness, and baseline scores on psychache, suicide ideation, depression, and hopelessness are statistically controlled.

5. In general, findings would not vary as a function of risk level. That is, consistent findings would emerge for general and high-risk students with regard to the previous hypotheses.

\section{Method}

\section{Participants}


From first-year university introductory psychology course subject pools totalling 4499 students, two samples were drawn. Each sample comprised $80 \%$ women which is slightly greater than the $72 \%$ typically found for these subject pools (Troister \& Holden, 2013). The general group $(N=683)$ ranged in age from 17 to 89 years $(M=18.23$, Median, Mode $=18)$. The highrisk group $(N=262)$ ranged in age from 17 to 34 years $(M=18.17$, Median, Mode $=18)$. All were treated according to University Research Ethics Board guidelines.

\section{Procedure}

Subject pool participants were initially assessed at baseline on all measures. They reported age and sex, indicated if they had ever attempted suicide and, if so, how long ago the most recent attempt was, the attempt method, how intent they were on dying in that attempt, and the number of lifetime attempts. In addition, individuals completed measures of suicide ideation, psychache, depression, and hopelessness described below. Five months later, participants were recruited to complete the same materials online. Individuals received either course credit or $\$ 10$ for this reassessment. For the general sample, participants were the first 683 individuals responding to mass emailings sent to all subject pool participants. In the high-risk sample, these participants were individually solicited for retesting if, at baseline, they (a) indicated a history of a suicide attempt, or (b) were considered suicide ideators, based on endorsing active or passive suicidal desire. Beck and Steer (1993) indicate this as a method for identifying suicide ideators.

\section{Measures}

The Psychache Scale (see Holden et al., 2001 for a list of all items) comprises 13 selfreport 5-point ratings (e.g., "My soul aches", "I hurt because I feel empty", "Psychologically, I feel terrible") assessing Shneidman's (1979) concept of psychache/psychological pain. Alpha reliabilities exceeding .90 are reported in university (Troister \& Holden, 2010) and offender 
(Mills et al., 2005) samples. Scale validity has been demonstrated through its ability to distinguish between suicide attempters and non-attempters (Holden et al., 2001).

The Beck Depression Inventory - II (BDI-II; Beck, Steer, \& Brown, 1996) is a 21-item, self-report measure of depression severity in the previous two weeks. Items are answered on 4point ratings. The scale has high internal reliability for psychiatric outpatients (Beck, Steer, Ball, \& Ranieri, 1996) and convergent and discriminant validity in uses with psychiatric inpatients.

The Beck Hopelessness Scale (BHS; Beck, Weissman, Lester, \& Trexler, 1974) is a 20item true/false self-report measure that assesses pessimism about the future. Scale alpha reliability for hospitalized suicide attempters was .93 . Validity for the BHS has been demonstrated by its ability to predict subsequent death by suicide (Beck et al., 1990).

As a suicidality criterion, the Beck Scale for Suicide Ideation (BSS; Beck \& Steer, 1993) comprises 19 self-report items measuring ideation and intent. Beck and Steer found alpha reliabilities over .85 for psychiatric patients and they reported that the self-report BSS correlated over .90 with a clinician-rated version used with psychiatric samples. Consistent with previous factor analyses (Holden \& DeLisle, 2005), the BSS was scored on subscales of Suicide Motivation and Suicide Preparation. Whereas the former measures more passive aspects of ideation such as ambiguity about living or dying, the latter quantifies a more active suicide component including planning the suicidal act.

\section{Results}

For the general sample, Table 1 reports scale statistics and correlations. Values are similar to those found for other student samples (DeLisle \& Holden, 2009; Troister \& Holden, 2010). Supporting Hypothesis 1, at baseline, psychache correlated significantly with total suicide ideation $(.52, p<.01)$, suicide motivation $(.48, p<.01)$ and suicide preparation $(.44, p<.01)$. 
Effect sizes were medium (i.e., > .30) to large (i.e., .50). In further support of Hypothesis 1, at 5month follow-up, psychache correlated significantly with total suicide ideation $(.58, p<.01)$, suicide motivation $(.52, p<.01)$ and suicide preparation $(.52, p<.01)$. Effect sizes were more than large.

Within the high-risk sample at baseline, suicide attempters and non-attempters did not differ significantly on psychache, $t(258)=1.07, p=.29$. For this high-risk group, 68 individuals (26\%) indicated a previous suicide attempt. The most common methods were pills (35\%) and cutting $(18 \%)$. Time since the last attempt averaged 36.72 months (Median $=36.00)$, intent for that attempt had a mean of 2.95 on a 5-point scale, and the number of lifetime attempts ranged from 1 to $17(M=1.64)$. Scale statistics and correlations for the high-risk sample are in Table 2. Mean values did not differ from those for other high-risk students (Troister \& Holden, 2012a) on depression, hopelessness, psychache, or suicide ideation (all $p \mathrm{~s}>.23$ ). Confirming our selection procedure, the difference in BSS scores between high-risk $(M=9.84)$ and the general students $(M=4.14)$ was more than large (Cohen's $d=1.85)$. This high-risk group BSS mean of 9.84 was similar to and did not differ significantly, $t(312)=1.61, p>.05$, from that of 11.23 reported in the BSS manual (Beck \& Steer, 1993, p. 15) for an outpatient ideator sample. Further verifying the nature of our high-risk group, relative to the general university group, the high-risk sample's scores on depression, hopelessness, and psychache all were significantly elevated with effect sizes greater than large (all Cohen's $d \mathrm{~s} \geq .92$ ). In addition, these high-risk sample means for these variables were similar to those previously reported for a sample of 179 suicide attempters (Flynn \& Holden, 2007). At baseline, psychache correlated significantly with total suicide ideation $(.54, p<.01)$, suicide motivation $(.54, p<.01)$ and suicide preparation $(.40, p<.01)$. Effect sizes were more than medium. At 5-month follow-up, psychache correlated significantly 
with total suicide ideation $(.62, p<.01)$, suicide motivation $(.60, p<.01)$ and suicide preparation $(.54, p<.01)$. Effect sizes were all large. All correlations were in accord with Hypothesis 1 .

In support of Hypothesis 2, for the general sample, at baseline when statistically partialling out depression and hopelessness, psychache correlated significantly with total suicide ideation $(.33, p<.01)$, suicide motivation $(.30, p<.01)$, and suicide preparation $(.29, p<.01)$. Effect sizes were approximately medium. Similarly, at 5-month follow-up, Hypothesis 2 was supported by significant correlations, controlling for depression and hopelessness, between psychache and total suicide ideation $(.23, p<.01)$, suicide motivation $(.13, p<.01)$, and suicide preparation $(.24, p<.01)$. Effect sizes were small to medium.

For the high-risk sample at baseline, partialling out depression and hopelessness, psychache correlated with total suicide ideation $(.28, p<.01)$, suicide motivation $(.25, p<.01)$, and suicide preparation $(.22, p<.01)$. All effects were slightly below medium. At 5-month follow-up controlling for depression and hopelessness, psychache correlated with total suicide ideation $(.21, p<.01)$, suicide motivation $(.14, p<.05)$, and suicide preparation $(.22, p<.01)$. Effect sizes were small to medium. All these correlations supported Hypothesis 2.

Due to distributional non-normality and to heteroscedasticity, multiple regression analysis with bootstrapping (10,000 resamples) was used to evaluate change. To test Hypothesis 3, follow-up scores on ideation were regressed on follow-up scores on psychache while covarying out corresponding baseline scores (Table 3). The standardized regression coefficient was then tested using a 95\% confidence interval. For the general sample, in support of Hypothesis 3, change in psychache significantly related to change in each of total suicide ideation $(\beta=.43, p<.05)$, suicide motivation $(\beta=.39, p<.05)$, and suicide preparation $(\beta=.37$, $p<.05)$. For the high-risk sample, also supporting Hypothesis 3 , change in psychache 
significantly related to change in each of total suicide ideation $(\beta=.50, p<.05)$, suicide motivation $(\beta=.49, p<.05)$, and suicide preparation $(\beta=.38, p<.05)$.

To evaluate Hypothesis 4, 5-month follow-up ideation scores were regressed on followup scores on psychache while covarying out follow-up scores on depression and hopelessness, and all corresponding baseline scores (Table 4). Again, due to non-normality and heteroscedasticity, bootstrapping (10,000 resamples) generated $95 \%$ confidence intervals that were used to evaluate significance. For the general sample, in partial support of Hypothesis 4, change in psychache was significantly related to change in total suicide ideation $(\beta=.24, p<$ $.05)$ and suicide preparation $(\beta=.26, p<.05)$ but not suicide motivation $(\beta=.16, p>.05)$. Similarly, for the high-risk sample, change in psychache was significantly associated with change in total suicide ideation $(\beta=.21, p<.05)$ and suicide preparation $(\beta=.21, p<.05)$ but not suicide motivation $(\beta=.14, p>.05)$.

\section{Discussion}

As a cause of death in the U.S. and Canada, suicide claims 85 Americans every day (Moscicki, 1999) and, annually, more than 3500 Canadians (Statistics Canada, 2007). As a risk factor for death by suicide and attempted death by suicide (Ranieri et al., 1987), suicide ideation constitutes an important antecedent variable for research as well as a mental health issue in itself. Understanding the psychological factors associated with suicide ideation and death by suicide can potentially highlight areas for therapeutic treatment and for the reduction of suicidality.

Suicide ideation and other suicidal manifestations are not uncommon phenomena among university students. For a sample of over 6100 students in the first month of university, Troister and Holden (2012b) reported substantial reliable variance on the BSS $(M=4.28 ; S D=5.49$; alpha reliability $=.78$ ) with $2.7 \%$ of students indicating a lifetime history of one suicide attempt 
and $1.1 \%$ reporting multiple attempts. Among these attempters $(n=167), 29 \%$ indicated the most recent attempt had occurred within the previous year.

As predictors of suicidal manifestations, prominent psychological factors are depression, hopelessness, and psychache. Published, empirical links between depression and suicide have a long history (e.g., Robins, Schmidt, \& O’Neil, 1957), although, in the last three decades, hopelessness or hopelessness depression has been identified as a relevant mediating variable (Abramson, Metalsky, \& Alloy, 1989) and predictive of eventual death by suicide (Beck, Brown, Berchick, Stewart, \& Steer, 1990; Beck, Brown, \& Steer, 1989). Notwithstanding the associations between hopelessness and suicide, Shneidman asserted that "Suicide is caused by psychache" (p. 145). Shneidman indicated that suicide is "not a psychiatric disorder" (p. 146) but an adjustive escape from unbearable psychological pain that is brought about by frustrated psychological needs. Accumulating research supports the assessment merit and added value (beyond depression and hopelessness) of psychache for indicating suicidality (DeLisle \& Holden, 2009; Holden et al., 2001; Troister \& Holden, 2010, 2013). This growing body of research, however, is limited by a preponderance of cross-sectional, rather than longitudinal, studies where testing of a priori causal models is less powerful. The current research contributes by evaluating associations longitudinally with moderately large samples and by doing so with both low and high-risk populations.

Generally, our findings support Shneidman's (1993) statement that psychache is the essential component of suicide. For each of low and high-risk samples, psychache and suicide ideation (both motivation and preparation) showed significant concurrent associations, with and without depression and hopelessness statistically controlled. In both low and high-risk samples, change in psychache correlated significantly with change in suicidality (again, for both 
motivation and preparation). Further, change in suicide preparation related significantly to change in psychache controlling for change in each of depression and hopelessness.

The only time psychache was not a significant predictor, was when depression and hopelessness were controlled in the prediction of change in suicide motivation. This specific lack of association replicated across the two samples of varying risk and the distinction between suicide motivation and suicide preparation supports the division of the BSS into two component subscales (Holden \& DeLisle, 2005). Further, concurrent research with students (Troister \& Holden, 2012a) and patients attending a psychiatric hospital crisis unit (Holden, Kerr, Mendonca, \& Velamoor, 1998) has reported a consistent increase in the importance of psychache (or internal perturbation) as lethality of suicidal manifestations intensifies from desire to actions.

The similarity of results for low risk and high-risk samples highlights the generalizability of Shneidman's model and supports the view that suicide is a general human problem rather than a psychiatric issue, per se. This congruence is also consistent with depression research where Vredenburg, Flett, and Krames (1993) have presented extensive data indicating similarities between non-clinical and clinical samples.

Although analyses, showing that change in psychache relates to change in suicide ideation and its subscales when controlling for change in depression and in hopelessness, support the relevance of psychache, findings do not entirely conform to Shneidman's theory. In asserting the pre-eminence of psychache for suicide, Shneidman maintained that all other factors associate with suicide only through psychache. As such, when psychache is statistically controlled, other factors should become statistically non-significant. This was not found - changes in depression or hopelessness retained their significance when psychache was statistically controlled in 7 of 12 instances (Table 4). The lack of non-significance for these other factors is also to be noted for 
other studies (e.g., Troister \& Holden, 2012a) and, rather than regarding psychache as a mediator, can be interpreted as depression, hopelessness, and psychache being nonredundant (DeLisle \& Holden, 2009) overlapping risk factors (Kraemer, Stice, Kazdin, Offord, \& Kupfer, 2001), where, although psychache may be dominant, its pre-eminence is not absolute.

With psychache as a suicide-relevant construct, Shneidman (2005) has indicated that the subsequent therapeutic task is identifying the frustrated psychological needs that are leading to this unbearable condition. Thwarted needs will differ among individuals manifesting suicide ideation and the anodynic goal will require determining the relevant frustrated need and developing an intervention dealing with that specific need for that particular individual. The effectiveness of such an approach, however, does remain to be empirically demonstrated.

Potential limitations to findings are to be noted as are directions for future research. First, samples studied here were university students and quite predominantly female. Notwithstanding Vredenburg et al.'s (1993) indication of similar findings for clinical and analogue populations, confirmation of present results with clinical and other at-risk (e.g., forensic) populations would evaluate the generalizability of present results. Furthermore, given large sex and age differences in rates of death by and attempted death by suicide, replications with male samples and samples of other ages (e.g., elderly) are areas for future research. Second, our criteria focused on selfreported suicide ideation. Although ideation is a precursor to more lethal suicide manifestations and a mental health issue in itself, it remains a proxy for death by suicide. Thus, despite increasing evidence for the relevance of psychache, a prospective study with death by suicide as an ultimate outcome (e.g., Brown et al., 2000) remains an important test for Shneidman's theory and for establishing the contributions of psychache relative to depression and hopelessness. The accumulating evidence, however, hints that such a study would have merit. 
Overall, in longitudinally testing Shneidman's model of psychache as a cause of suicide, present results contribute by detailing, in the first large-scale longitudinal investigation, how change in suicide ideation relates to change in psychache with and without controlling for other suicide-relevant factors. Furthermore, in finding general support for Shneidman's concept of psychache, similarities between analogue and high-risk populations are demonstrated, and differences between subcomponents of suicide ideation are confirmed. 


\section{References}

Abramson, L. Y., Metalsky, G. I., \& Alloy, L. B. (1989). Hopelessness depression: A theorybased subtype of depression. Psychological Review, 96, 358-372.

Beck, A. T., Brown, G., Berchick, R. J., Stewart, B. L., \& Steer, R. A. (1990). Relationship between hopelessness and ultimate suicide: A replication with psychiatric outpatients. American Journal of Psychiatry, 147, 190-195.

Beck, A. T., \& Steer, R. A. (1993). Beck Scale for Suicide Ideation manual. San Antonio, TX: Psychological Corporation.

Beck, A. T., Steer, R. A., Ball, R., \& Ranieri, W. F. (1996). Comparison of Beck Depression Inventories -IA and -II in psychiatric outpatients. Journal of Personality Assessment, 67, 588-597.

Beck, A. T., Steer, R. A., \& Brown, G. K. (1996). Manual for the Beck Depression Inventory-II. San Antonio, TX: Psychological Corporation.

Beck, A. T., Weismann, A., Lester, D., \& Trexler, L. (1974). The measurement of pessimism: The Hopelessness Scale. Journal of Consulting and Clinical Psychology, 42, 861-865.

Brown, G. K., Beck, A. T., Steer, R. A., \& Grisham, J. R. (2000). Risk factors for suicide in psychiatric outpatients: A 20-year prospective study. Journal of Consulting and Clinical Psychology, 68, 371-377.

DeLisle, M. M., \& Holden, R. R. (2009). Differentiating between depression, hopelessness, and psychache in university undergraduates. Measurement and Evaluation in Counseling and Development, 42, 46-63. 
Flynn, J., \& Holden, R. R. (2007, June). Predictors of suicidality in a sample of suicide attempters. Presented at the Canadian Psychological Association Annual Convention, Ottawa, Canada.

Holden, R. R., \& DeLisle, M. M. (2005). Factor analysis of the Beck Scale for Suicide Ideation with female suicide attempters. Assessment, 12, 231-238.

Holden, R. R., Kerr, P. S., Mendonca, J. D., \& Velamoor, V. R. (1998). Are some motives more linked to suicide proneness than others? Journal of Clinical Psychology, 54, 569-576.

Holden, R. R., Mehta, K., Cunningham, E. J., \& McLeod, L. D. (2001). Development and preliminary validation of a scale of psychache. Canadian Journal of Behavioural Science, 33, 224-232.

Kessler, R. C., Berglund, P., Borges, G., Nock, M., \& Wang, P. S. (2005). Trends in suicide ideation, plans, gestures, and attempts in the United States, 1990-1992 to 2001-2003. Journal of the American Medical Association, 293, 2487-2495.

Kraemer, H. C., Stice, E., Kazdin, A., Offord, D., \& Kupfer, D. (2001). How do risk factors work together? Mediators, moderators, and independent, overlapping, and proxy risk factors. American Journal of Psychiatry, 158, 848-856.

Mills, J. F., Green, K., \& Reddon, J. R. (2005). An evaluation of the Psychache Scale on an offender population. Suicide and Life-Threatening Behavior, 35, 570-580.

Moscicki, E. K. (1997). Identification of suicide risk factors using epidemiologic studies. Psychiatric Clinics of North America, 20, 499-517.

Moscicki, E. K. (1999). Epidemiology of suicide. In D. G. Jacobs (Ed.), The Harvard Medical School guide to suicide assessment and intervention (pp. 40-51). San Francisco: JosseyBass. 
National Institute of Mental Health (n.d.). Suicide in the U.S.: Statistics and prevention. Retrieved from http://www.nimh.nih.gov/health/publications/suicide-in-the-us-statisticsand-prevention/index.shtml

Ranieri, W. F., Steer, R. A., Lavrence, T. I., Rissmiller, D. J., Piper, G. E., \& Beck, A. T. (1987). Relationships of depression, hopelessness, and dysfunctional attitudes to suicide ideation in psychiatric patients. Psychological Reports, 61, 967-975.

Robins, E., Schmidt, E. H., \& O’Neil, P. (1957). Some interrelations of social factors and clinical diagnosis.: A study of 109 patients. American Journal of Psychiatry, 114, 221-231.

Shneidman, E. S. (1993). Suicide as psychache. The Journal of Nervous and Mental Disease, $181,145-147$.

Shneidman, E. S. (2005). Anodyne psychotherapy for suicide: A psychological view of suicide. Clinical Neuropsychiatry, 2, 7-12.

Statistics Canada (2007). Leading causes of deaths in Canada, 2007. Ottawa: Government of Canada.

Thomson, W. (2012). Long term follow up of suicide in a clinically depressed community sample. Journal of Affective Disorders, 139, 52-55.

Troister, T., \& Holden, R. R. (2010). Comparing psychache, depression, and hopelessness in their associations with suicidality: A test of Shneidman's theory of suicide. Personality and Individual Differences, 49, 689-693.

Troister, T., \& Holden, R. R. (2012a). A two-year prospective study of psychache and its relationship to suicidality among high-risk undergraduates. Journal of Clinical Psychology, 68, 1019-1027. 
Troister, T., \& Holden, R. R. (2012b, July). Suicide ideation in transitioning university undergraduates. Presented at the International Congress of Psychology, Cape Town, South Africa.

Troister, T., \& Holden, R. R. (2013). Factorial differentiation among depression, hopelessness, and psychache in statistically predicting suicidality. Measurement and Evaluation in Counseling and Development, 46, 50-63.

Vredenburg, K., Flett, G. L., \& Krames, L. (1993). Analogue versus clinical depression: A critical reappraisal. Psychological Bulletin, 113, 327-344.

World Health Organization. (2002) World report on violence and health. Geneva: World Health Organization. 
Table 1

Scale Correlations, Coefficient Alpha Reliabilities, Means, and Standard Deviations ( $N=683$ Undergraduates)

\begin{tabular}{clllllllllll}
\hline Scale & 1 & 2 & 3 & 4 & 5 & 6 & 7 & 8 & 9 & 10 & 11 \\
\hline
\end{tabular}

$\underline{\text { Baseline }}$

1. Beck Depression Inventory $\quad .86$

2. Beck Hopelessness Scale $\quad .45 \quad .83$

3. Psychache Scale $\quad .61 \quad .50 \quad .95$

$\begin{array}{lllll}\text { 4. Beck Scale for Suicide Ideation } \quad .36 & .48 & .52 & .78\end{array}$

$\begin{array}{lllllll}\text { 5. Suicide Motivation Subscale } & .31 & .49 & .48 & .83 & .73\end{array}$

$\begin{array}{llllllll}\text { 6. Suicide Preparation Subscale } & .29 & .35 & .44 & .90 & .59 & .63\end{array}$

5-month follow-up

7. Beck Depression Inventory

.56

$.43 \quad .42$

$.34 \quad .92$

8. Beck Hopelessness Scale

.39

$.63 \quad .46$

$.45 \quad .46$

$.36 \quad .66$

.85

9. Psychache Scale

$.41 \quad .65$

.44

.41

.37

.60

.95 


\begin{tabular}{|c|c|c|c|c|c|c|c|c|c|c|c|c|}
\hline 10. Beck Scale for Suicide Ideation & .31 & .42 & .43 & .70 & .60 & .65 & .59 & .55 & .58 & .79 & & \\
\hline 11. Suicide Motivation Subscale & .28 & .40 & .38 & .59 & .61 & .50 & .56 & .58 & .52 & .87 & .74 & \\
\hline 12. Suicide Preparation Subscale & .25 & .34 & .40 & .67 & .51 & .69 & .49 & .43 & .52 & .91 & .67 & .64 \\
\hline$M$ & 7.83 & 3.31 & 20.25 & 4.14 & 0.74 & 2.56 & 10.13 & 3.61 & 20.58 & 4.22 & 0.84 & 2.59 \\
\hline$S D$ & 6.23 & 3.24 & 8.37 & 3.68 & 1.55 & 2.12 & 9.08 & 3.69 & 8.71 & 3.73 & 1.66 & 2.14 \\
\hline
\end{tabular}

Note. 5-month test-retest correlations are in bold. Coefficient alpha reliabilities are in the diagonal. All correlations are significant at the .01 level. 
Table 2

Scale Correlations, Coefficient Alpha Reliabilities, Means, and Standard Deviations ( $N=262$ High-Risk Undergraduates)

\begin{tabular}{llllllllllll}
\hline Scale & 1 & 2 & 3 & 4 & 5 & 6 & 7 & 8 & 9 & 10 & 11 \\
\hline
\end{tabular}

$\underline{\text { Baseline }}$

1. Beck Depression Inventory $\quad .9$

2. Beck Hopelessness Scale $\quad .57 \quad .88$

3. Psychache Scale $\quad .66 \quad .49 \quad .95$

$\begin{array}{llllll}\text { 4. Beck Scale for Suicide Ideation } & .48 & .53 & .54 & .83\end{array}$

$\begin{array}{lllllll}\text { 5. Suicide Motivation Subscale } & .50 & .56 & .54 & .88 & .79\end{array}$

$\begin{array}{lllllll}\text { 6. Suicide Preparation Subscale } & .34 & .34 & .40 & .88 & .61 & .74\end{array}$

5-month follow-up

7. Beck Depression Inventory

.68

$.45 \quad .51$

$.45 \quad .42$

$.38 \quad .95$

8. Beck Hopelessness Scale

.56

49

$.48 \quad .49$

$.36 \quad .70$

.90

9. Psychache Scale

59

$.39 \quad .67$

.67

$.47 \quad .44$

$.41 \quad .81$

.66

.96 


\begin{tabular}{|c|c|c|c|c|c|c|c|c|c|c|c|c|}
\hline 10. Beck Scale for Suicide Ideation & .42 & .41 & .44 & .65 & .54 & .63 & .62 & .59 & .62 & .87 & & \\
\hline 11. Suicide Motivation Subscale & .46 & .44 & .44 & .59 & .58 & .50 & .62 & .62 & .60 & .91 & .84 & \\
\hline 12. Suicide Preparation Subscale & .30 & .30 & .37 & .62 & .44 & .70 & .51 & .47 & .54 & .92 & .72 & .74 \\
\hline$M$ & 14.39 & 5.76 & 28.01 & 9.84 & 3.45 & 5.40 & 16.02 & 6.89 & 27.71 & 8.51 & 2.85 & 4.79 \\
\hline$S D$ & 9.64 & 4.67 & 11.20 & 5.47 & 3.00 & 3.10 & 12.16 & 5.17 & 11.38 & 6.09 & 3.19 & 3.30 \\
\hline
\end{tabular}

Note. 5-month test-retest correlations are in bold. Coefficient alpha reliabilities are in the diagonal. All correlations are significant at the .01 level. 
Table 3

Standardized Regression Coefficients for Statistically Predicting Change in Suicidality from Change in Psychache

\begin{tabular}{|c|c|c|c|c|c|}
\hline \multicolumn{3}{|c|}{$N=683$ Undergraduates } & \multicolumn{3}{|c|}{$N=262$ High-Risk Undergraduates } \\
\hline \multicolumn{6}{|c|}{$\underline{\text { 5- month Follow-up Suicide Criterion }}$} \\
\hline $\begin{array}{c}\text { Total Suicide } \\
\text { Ideation }\end{array}$ & $\begin{array}{c}\text { Suicide } \\
\text { Motivation } \\
\underline{\text { Subscale }}\end{array}$ & $\begin{array}{c}\text { Suicide } \\
\text { Preparation } \\
\text { Subscale }\end{array}$ & $\begin{array}{c}\text { Total Suicide } \\
\underline{\text { Ideation }}\end{array}$ & $\begin{array}{c}\text { Suicide } \\
\text { Motivation } \\
\text { Subscale }\end{array}$ & $\begin{array}{c}\text { Suicide } \\
\text { Preparation } \\
\text { Subscale }\end{array}$ \\
\hline .60 & .47 & .57 & .57 & .49 & .58 \\
\hline
\end{tabular}

\section{$\underline{\text { Predictor }}$}

Baseline BSS Scale

Baseline Psychache Scale

5-month follow-up Psychache Scale
$.61 *$

$-.19 *$

$.43 *$
$.52 *$

$-.13 *$

$.39 *$
$.61 *$

$-.11 *$

$.37^{*}$
$.51 *$

$.43 *$

$.60 *$

$-.18 *$

$-.12$

$-.14 *$

$.50 *$

$.49 *$ 
$* p<.05$.

Note. Statistical significance of regression coefficients was tested through bootstrapping (10,000 resamples). Significance for the psychache regression coefficient at follow-up controlling for baseline psychache and baseline BSS scale indicates that change in psychache correlates significantly with change in the BSS scale. 
Table 4

Standardized Regression Coefficients for Predicting Change in Suicide Ideation from Change in Psychache Controlling for Change in Depression and Change in Hopelessness

$\underline{N=683 \text { Undergraduates } \quad N=262 \text { High-Risk Undergraduates }}$

$\underline{\text { 5-month Follow-up Suicide Criterion }}$

\begin{tabular}{|c|c|c|c|c|c|c|}
\hline & $\begin{array}{c}\text { Total } \\
\text { Suicide } \\
\text { Ideation }\end{array}$ & $\begin{array}{c}\text { Suicide } \\
\text { Motivation } \\
\underline{\text { Subscale }}\end{array}$ & $\begin{array}{c}\text { Suicide } \\
\text { Preparation } \\
\underline{\text { Subscale }}\end{array}$ & $\begin{array}{c}\text { Total } \\
\text { Suicide } \\
\text { Ideation }\end{array}$ & $\begin{array}{c}\text { Suicide } \\
\text { Motivation } \\
\text { Subscale }\end{array}$ & $\begin{array}{c}\text { Suicide } \\
\text { Preparation } \\
\underline{\text { Subscale }}\end{array}$ \\
\hline$R^{2}$ & .57 & .45 & .51 & .61 & .58 & .61 \\
\hline
\end{tabular}

Predictor

Baseline BSS Scale

$.51^{*}$

$.38^{*}$

$.55^{*}$

$.47^{*}$

$.38^{*}$

$.58^{*}$

Baseline Depression Scale

$-.14^{*}$

$-.07$

$-.13^{*}$

$-.12$

$-.07$

$-.13$

Baseline Hopelessness

$-.01$

$-.06$

$-.01$

$-.07$

$-.08$

$-.05$

Scale

Baseline Psychache Scale

$-.12 *$

$-.08$

$-.07$

$-.07$

$-.01$

$-.07$

5-month follow-up

$.28 *$

$.22 *$

$.22^{*}$

.22

$.23 *$

.14

Depression Scale

5-month follow-up

.09

$.24 *$

.00

$.24 *$

$.31 *$

.17

Hopelessness Scale

5-month follow-up

$.24 *$

.16

$.26^{*}$

$.21 *$

.14

$.21 *$

Psychache Scale 
${ }^{*} p<.05$.

Note. Tests of significance are based on bootstrapping. Significance for the psychache regression coefficient at follow-up evaluates whether change in psychache correlates significantly with change in the BSS scale controlling for changes in depression and hopelessness. 


\section{CHAPTER 5: GENERAL DISCUSSION}

The general purpose of the three studies was to examine the relationship of psychache to suicidal outcomes. To accomplish this goal, three related empirical studies were conducted. These studies built on past research in the area of suicidology, and also contributed new knowledge to our understanding of psychache. Overall, results indicated that psychache is a distinct variable, though highly related to depression and hopelessness. Across all three studies, psychache was found to be a significant predictor of all suicidal behaviours, and longitudinal results provide preliminary support for psychache as a causal factor towards suicidality. Mixed results were found in regard to psychache being a full mediator in the relationship between depression and hopelessness and suicidal outcomes.

The first study utilized a large general sample of undergraduate students who were assessed at one time point. Participants self-reported on levels of depression, hopelessness, psychache, and suicidal ideation. This large sample size allowed for a factor analysis, in order to better understand the relationships between depression, hopelessness, and psychache. In addition, the contributions of these three psychological variables to the prediction of suicide ideation, and its subscales of motivation and preparation, could be examined. This study supported the results of past research (DeLisle \& Holden, 2009) and extended findings by examining the equality of regression coefficients in order to demonstrate differential strengths in statistically predicting different forms of suicidal ideation.

The results of the first study indicated that depression, hopelessness, and psychache are three distinct, correlated factors. This finding was confirmed by several methods. First, both exploratory and confirmatory factor analysis indicated best fit for a model with three correlated factors. Additionally, each of the three variables contributed significantly to the prediction of 
suicide ideation, suicide motivation, and suicide preparation, indicating that the three factor solution was based on the different content of the scales, and not on stylistic differences. Further verifying the distinctness of the factors, the variables differentially predicted different outcome variables. This finding would not emerge if depression, hopelessness, and psychache represented the same underlying construct. This study was therefore able to show, in a number of analyses, that psychache is distinct from depression and hopelessness and therefore merits consideration as a unique predictor of suicide risk.

Although the main goal of this study was to demonstrate the uniqueness of psychache, the study also allowed for an evaluation of Shneidman's theory that psychache is the most proximal predictor of suicide. Results supported Shneidman in that the psychache factor added unique contribution to the prediction of suicide ideation, motivation, and preparation. However, psychache did not fully mediate the associations of depression and hopelessness with suicidal outcomes, indicating that these two variables are also important in the prediction of suicide risk. When comparing coefficients, hopelessness emerged as the most important predictor of suicide motivation and psychache was the most important predictor of suicide preparation. The preparation subscale examines more lethal forms of suicidality than does the motivation scale, and therefore, this finding may indicate that as the suicidal behaviours become more serious, psychache becomes more important. However, this hypothesis needs to be confirmed with further research.

The second study is the first to examine psychache in a longitudinal fashion with at-risk students. Individuals were identified as being relatively high-risk based on a past suicide attempt or current suicidal ideation. Participants were followed for two years and self-reported on levels of depression, hopelessness, psychache, and suicide ideation. Results indicated that, after 
controlling for all baseline measures, as well as depression and hopelessness at follow-up, psychache was a significant predictor of suicide ideation. In further support of Shneidman's theory, neither depression nor hopelessness remained a significant predictor when the role of psychache was considered. These results held consistent when using change scores and when controlling for baseline scores. This study provides further support to psychache being considered alongside depression and hopelessness as an important factor in predicting suicide risk. The main contribution of this study is its design. By using a prospective design, this study allows for a stronger basis for making causal inferences by demonstrating that psychache and suicide ideation change together over two years.

The final study was another longitudinal study that examined the importance of psychache as a predictor of suicide ideation and assessed its importance relative to depression and hopelessness. Undergraduate students were followed for a shorter time period of five months, but a larger sample size was obtained. Both general and high-risk samples were examined so that comparisons could be made between results for the two groups.

One important finding from this study was the similarity of results between the two groups, indicating that Shneidman's model of suicide is generalizable. This result is consistent with data from Vredenburg, Flett, and Krames (1993) who were able to show the similarities between non-clinical and clinical samples. This congruence lends credence to the notion that the research conducted on psychache with low risk samples is likely applicable to clinical samples as well. With regard to the importance of psychache, findings provided mixed support for Shneidman's model. When controlling for changes in depression and hopelessness, change in psychache did contribute to the prediction of change in suicide ideation, indicating that psychache should be considered an important risk factor alongside depression and hopelessness. 
However, in over half the analyses, depression or hopelessness maintained significant predictive value as well, indicating that all three variables should be considered in risk prediction.

Based on the results of these three studies, several conclusions can be drawn: 1) psychache is distinct from both depression and hopelessness, but all three represent highly correlated factors; 2) psychache is positively related to suicidal ideation, motivation, and preparation; 4) levels of psychache and suicidal ideation change together over time; 4) psychache does merit consideration alongside depression and hopelessness as a pre-eminent psychological risk factor for suicidal outcomes; 5) when examining psychache in low risk samples, results likely apply to more clinical samples; 6) psychache may not always mediate the relationship between depression and hopelessness and suicidal outcomes, however, evidence is growing that psychache is the most important of the three psychological predictors.

\section{Theoretical Implications}

The three studies all examined Edwin Shneidman's theory of psychache and its relationship to suicidality. Shneidman postulated that psychache, or psychological pain, is the most proximal cause of suicide and would therefore be the most strongly linked to suicidal outcomes. He argued that all other predictors of suicide are secondary, and are only important insofar as their relationship to psychache and was quoted as saying "no psychache, no suicide" (Shneidman, 1999, p.87). If Shneidman were correct, it would be expected that psychache would mediate the relationship between all other psychological predictors and suicidality.

Findings from the three current studies provide partial support for Shneidman's model of suicide. In regard to his assertion that psychache is related to suicide, findings were unequivocal. In all analyses, across all three studies, psychache was positively correlated with all suicidal outcomes. Shneidman's claim that depression and hopelessness are only related to suicidal 
outcomes in terms of their relationship to psychache was not fully supported. In study two, results did support this theory, as the inclusion of psychache into the regression equations, resulted in nonsignificant prediction from both depression and hopelessness. This finding remained true when predicting total suicide ideation as well as each of its subscales. However, in the first study, depression and hopelessness retained significant value as predictors of suicidal outcomes. Furthermore, mediation analysis did not suggest that psychache fully mediated the relationships between depression and hopelessness and suicidal behaviours. Similarly, in the third study, depression and hopelessness retained significance in the prediction of suicidal outcomes after psychache was included in the model. These findings indicate that the best way to view psychache is as an important, non-overlapping risk factor, alongside depression and hopelessness.

Shneidman also postulated that psychache is the most important psychological predictor of suicidality. If his claim were correct, one would assume that psychache would remain a significant predictor of suicidal outcomes even when considering depression and hopelessness. In most analyses across the three studies, psychache did retain its significance as a predictor of suicidality after the inclusion of depression and hopelessness. However, in study three, two analyses saw psychache lose its significant contribution when follow-up scores on depression and hopelessness were included. This finding occurred when the outcome variable was suicide motivation and the same result was found for both low and higher risk samples. However, with both samples, psychache retained its significance after the inclusion of depression and hopelessness when examining suicide preparation and the total suicide ideation score.

The motivation subscale of the Beck Scale for Suicide Ideation asks about less lethal forms of ideation such as passive ideation, while the preparation scale assesses more serious 
suicidal behaviours such as whether someone has ever made the necessary arrangements for a suicide attempt. Therefore, the preparation scale is considered to assess more serious forms of suicidal ideation. The finding that psychache is more associated with suicide preparation, whereas hopelessness is more related to motivation, indicates that psychache is better able to predict more lethal behaviour. Although the current studies do not examine death by suicide, it may be the case that as individuals' actions move towards death by suicide, the importance of psychache relative to hopelessness will continue to increase.

The finding that psychache is the best predictor of suicide preparation has also been found in other studies. In several studies, internal perturbation-based reasons for attempting suicide were related to more lethal suicide actions, whereas hopelessness clustered with less intense behaviours (Holden et al., 1998; Holden \& Kroner, 2003; Johns \& Holden, 1997). A similar result was also shown in study one. Although psychache retained significant contribution in the prediction of suicide motivation, when evaluating the size of standardized regression coefficients, hopelessness had a significantly larger coefficient than that of either psychache or depression. However, when examining suicide preparation, the regression coefficient for psychache was significantly larger than the coefficient for hopelessness and depression. Taken together, results point to psychache being associated with more lethal forms of suicidality. Although this hypothesis awaits further study that includes death by suicide, this preliminary finding adds support to Shneidman's (1993) notion that psychache is the factor most strongly associated with suicide.

\section{Clinical Implications}

Suicide takes the lives of 1 million people worldwide each year (World Health Organization, 2002) and is one of the 10 leading causes of death in Canada (Statistics Canada, 
2011). In addition to death by suicide, parasuicidal behaviours represent an important mental health concern, and one that is prevalent in university populations. Research has shown that approximately $10 \%$ of undergraduate students in a first-year psychology class report a past suicide attempt (Flamenbaum \& Holden, 2007), with even higher numbers of students reporting suicidal ideation. These statistics make clear the need for a better understanding of causes for suicidal behaviours. More specifically, an understanding of psychological predictors that are amenable to change is crucial in order to inform efforts at prevention, assessment, and intervention.

Assessment

One of the first steps towards preventing suicide is the accurate prediction of who is at highest risk. Currently, the BDI, BHS, and BSS are all tools utilized to predict who is most likely to display suicidal behaviours. Unfortunately, although these measures can provide some information on risk, no instrument alone, or instruments combined, is perfectly accurate (Baumeister, 1990; Beck, Steer, Kovacs \& Garrison, 1985). With such a low base rate for suicide, accurate prediction of who will attempt and die by suicide is extremely difficult. The present studies indicate that the Psychache Scale merits use alongside the above-mentioned tools in the assessment of suicide risk. Study one confirms and extends previous research (DeLisle \& Holden, 2009) indicating that psychache is a distinct variable from depression and hopelessness, and that therefore, the Psychache Scale adds non redundant predictive value to the assessment of suicide risk. Given its strong psychometric properties and quick administration time, the Psychache Scale shows potential as a clinical tool. Further research on the scale examining suicide attempts and death by suicide will help establish norms and cut-off criteria to aid in interpretation of the measure. 


\section{Intervention}

Results of the presented studies also have implications for the treatment of suicidal individuals. The unique contribution of psychache to the prediction of suicide risk indicates that psychache may be an important tool in intervention. First, given that psychache has been shown to be related to suicidal outcomes in numerous studies, psychological pain is clearly an important concept to broach with suicidal clients. Mental health professionals, unaware of the concept of psychological pain, may focus on symptoms of depression, or hopeless cognitions, and may miss out on asking clients about their level of pain. Having a term, psychache, by which to discuss this pain, will serve to validate the experiences of clients with suicidal ideation, make them feel understood, and possibly increase the therapeutic alliance. It is clear from past research that people do experience mental pain (Leenaars, 1991), and it is important for mental health professionals to be aware of and ask about the impact of this pain.

In terms of treatment for suicidal individuals, Shneidman believed that the most appropriate intervention for suicide is something he termed anodynic psychotherapy (Shneidman, 2005), where anodynic means therapy targeted at reducing pain, with the goal of reducing the likelihood of suicide. In Shneidman's model of suicide, he postulated that the cause of suicide is unfulfilled psychological needs. He identified a number of needs particularly relevant for suicide, adapted from Murray's (1938) need theory of personality, including: affiliation, succorance (the act of seeking out social support), achievement, autonomy, order, understanding, defendence, nurturance, dominance, aggression and shame-avoidance. Thus, Shneidman's suggested focus of treatment is on an individual's specific unmet needs. He believed that if these needs can be better met, psychache, and consequently suicide, will be reduced. 
Unfortunately, Shneidman's recommended treatment approach was never studied empirically, nor did he ever outline exactly how the frustrated needs should be met.

Current approaches to treating suicidal individuals focus on cognitive-behavioural therapy and problem-solving approaches (Brown et al., 2005; Eskin, Ertekin, \& Demir, 2008). CBT has been shown to be effective in reducing suicidal outcomes (Brown et al.) by identifying thoughts that occurred prior to a past attempt and finding adaptive ways to cope with stressors. Studies have found that cognitively-oriented therapies have outperformed conventional approaches to treating suicidal individuals (Ellis \& Rutherford, 2008). Shneidman's suggested therapy for the amelioration of psychache could be incorporated into CBT approaches. Frustrated needs could be addressed by identifying maladaptive thoughts that may prevent the individual from meeting their need. For example, an individual with a frustrated need for achievement may have the thought "if I don't get into medical school I am a failure." This thought could be examined through CBT techniques and a more realistic thought could be created. Behavioural strategies could also be used to test out maladaptive thoughts and help suicidal individuals get their frustrated needs met. By meeting these needs, psychache would be reduced, and suicide will be less likely. Although some research has shown psychache to be related to unfulfilled needs (Davie, 2005; Flamenbaum \& Holden, 2007), more research is needed to demonstrate this relationship and to empirically validate therapeutic techniques aimed at reducing psychache.

\section{Limitations}

This group of studies has a number of limitations based on the type of samples, utilized materials and study design. All three studies examined an undergraduate population with a limited age range and fewer men than women. Therefore the results may not be generalizable to populations with different demographic characteristics. Study three shows that results from 
general samples are highly similar to at-risk samples and suggests that results from study one would also apply to higher risk samples. These results align with other research showing consistent results between analogue and clinical samples in depression research (Vredenburg, Flett, \& Krames, 1993). Despite these findings, more research on psychache in clinical samples is needed in order to confirm generalizability of results.

Another limitation of all three studies is that suicidality was defined by the outcome variable of suicide ideation and its subscales, suicide motivation and suicide preparation. Therefore, the current results do not allow for definitive conclusions on psychache's ability to predict death by suicide. Research has shown that past suicidal behaviours, such as ideation and attempts, are the best predictors of future suicide (Joiner et al., 2005), and that the risk of attempted suicide has been found to increase 3 to 17 times in those with prior suicidal behaviour (Gould, Greenberg, Velting, \& Shaffer, 2003). However, not everyone who dies by suicide has made a past attempt. It is unclear if all suicidal outcomes fall on a continuum and can be predicted by similar factors, or if death by suicide represents a distinct category with distinct risk factors. Though the suicidal outcomes used in the current studies are not perfect proxies for death by suicide, thoughts of killing oneself, and actions associated with a suicide attempt, are significant mental health concerns in their own right and therefore warrant investigation.

\section{Future Research}

Studies two and three are the first published research articles that examine psychache longitudinally in suicide ideators. These prospective designs are the first step towards an understanding of the relationships between depression, hopelessness, and psychache over time, and how they cause suicidal behaviours. Although this is a step in the right direction, more longitudinal research is needed over longer time periods and with different types of samples. 
By conducting prospective studies with large samples and over a long time span, the link between psychache and death by suicide can be elucidated. Although the study of parasuicidal behaviours still warrants attention, Shneidman's theory can only truly be tested when suicide is the outcome studied. Beck and colleagues were able to demonstrate the pre-eminence of hopelessness in the prediction of suicide with large sample sizes and participants that were followed for up to 20 years (Brown et al., 2000). Research of this type, with psychache included alongside depression and hopelessness, will provide an understanding of how these variables are implicated in suicide, and, in particular, will help uncover the importance of psychache as a risk factor. 


\section{References}

Baumeister, R. F. (1990). Suicide as escape from self. Psychological Review, 97, 90-113.

Beck, A. T. (1963). Thinking and depression: I. Idiosyncratic content and cognitive distortions. Archives of General Psychiatry, 9, 324-33.

Beck, A. T., Brown, G. K., \& Steer, R. A. (1989). Prediction of eventual suicide in psychiatric inpatients by clinical ratings of hopelessness. Journal of Consulting and Clinical Psychology, 57, 309-310.

Beck, A. T., \& Lester, D. (1973). Components of depression in attempted suicides. Journal of Psychology: Interdisciplinary and Applied, 85, 257-260.

Beck, A. T., Steer, R. A., Kovacs, M., \& Garrison, B. (1985). Hopelessness and eventual suicide: A 10-year prospective study of patients hospitalized with suicide ideation. American Journal of Psychiatry, 142, 559-563.

Berlim, M. T., Mattevi, B. S., Pavanello, D. P., Caldieraro, M. A., Fleck, M. P. A., Wingate, L. R., \& Joiner, T. E. Jr. (2003). Psychache and suicidality in adult mood disordered outpatients in Brazil. Suicide and Life-Threatening Behavior, 33, 242-248.

Bradvick, L., Mattisson, C., Bogren, M., \& Nettelbladt, P. (2008). Long-term suicide risk of depression in the Lundby cohort 1947-1997-Severity and gender. Acta Psychiatrica Scandinavica, 117, 185-191.

Brown, G. K., Beck, A. T., Steer, R. A., \& Grisham, J. R. (2000). Risk factors for suicide in psychiatric outpatients: A 20-year prospective study. Journal of Consulting and Clinical Psychology, 68, 371-377.

Brown, G. K., Ten Have, T., Henriques, G. R., Xie, S. X., Hollander, J. E., \& Beck, A. T. (2005). 
Cognitive therapy for the prevention of suicide attempts: A randomized controlled trial. Journal of the American Medical Association, 294, 563-570.

Cheng, A. T. A., Chen, T. H. H., Chen, C.-C., \& Jenkins, R. (2000). Psychosocial and psychiatric risk factors for suicide: Case-control psychological autopsy. British Journal of Psychiatry, 177, 360-365.

Crosby, A. E., Han, B., Ortega, L. A. G., Parks, S. E., Gfoerer, J. (2011). Suicidal thoughts and behaviors among adults aged $\geq 18$ years-United States, 2008-2009. Morbidity and Mortality Weekly Report, 1-22.

Davie, B. J. (2005). “Never a 'needless' suicide”: An empirical test of Shneidman's theory of psychological needs, psychological pain, and suicidality. Unpublished doctoral thesis. University of Windsor, Windsor, Ontario, Canada.

DeLisle, M. M., \& Holden, R. R. (2009). Differentiating between depression, hopelessness, and psychache in university undergraduates. Measurement and Evaluation in Counseling and Development, 42, 46-63.

Ellis, T. E. \& Rutherford, B. (2008). Cognition and suicide: Two decades of progress. International Journal of Cognitive Therapy, 1, 47-68.

Eskin, M., Ertekin, K., \& Demir, H. (2008). Efficacy of a problem-solving therapy for depression and suicide potential in adolescents and young adults. Cognitive Therapy and Research, 32, 227-245.

Flamenbaum, R., \& Holden, R. R. (2007). Psychache as a mediator in the relationship between perfectionism and suicidality. Journal of Counseling Psychology, 54, 51-61.

Flynn, J. J., \& Holden, R. R. (2007). Predictors of suicidality in a sample of suicide attempters. Canadian Psychology, 48:2a, 317. 
Gould, M. S., Greenberg, T., Velting, D. M., \& Shaffer, D. (2003). Youth suicide risk and preventative interventions: A review of the past 10 years. Journal of the American Academy of Child and Adolescent Psychiatry, 42, 386-405.

Harkavy-Friedman, J. M., Nelson, E. A., Venarde, D. F., \& Mann, J. J. (2004). Suicide behaviour in schizophrenia and schizoaffective disorder: Examining the role of depression. Suicide and Life-Threatening Behavior, 34, 66-76.

Health Canada (1994). Suicide in Canada: Update of the Report of the Task Force on Suicide in Canada. Ottawa: Minister of National Health and Welfare.

Holden, R. R., Kerr, P. S., Mendonca, J. D., \& Velamoor, V. R. (1998). Are some motives more linked to suicide proneness than others? Journal of Clinical Psychology, 54, 569-576.

Holden, R. R., \& Kroner, D. G. (2003). Differentiating suicidal motivations and manifestations in a forensic sample. Canadian Journal of Behavioural Science, 35, 35-44.

Holden, R. R., Mehta, K., Cunningham, E. J., \& McLeod, L. D. (2001). Development and preliminary validation of a scale of psychache. Canadian Journal of Behavioural Science, 33, 224-232.

Johns, D., \& Holden, R. R. (1997). Differentiating suicidal motivations and manifestations in a nonclinical population. Canadian Journal of Behavioural Science, 29, 266-274.

Joiner, T. E. Jr., Conwell, Y., Fitzpatrick, K. K., Witte, T. K., Schmidt, N. B., Berlim, M. T., Fleck, M. P. A., \& Rudd, M. D. (2005). Four studies on how past and current suicidality relate even when "everything but the kitchen sink" is covaried. Journal of Abnormal Psychology, 114, 291-203. 
Keefer, K. V., Holden, R. R., \& Gillis, K. (2009, June). The mediational role of psychache in the relationship between alexithymia and suicidal ideation. Canadian Psychological Association Annual Convention, Montreal, Canada.

Leenaars, A. A. (1991). Suicide notes and their implication for intervention. Crisis: The Journal of Crisis Intervention and Suicide Prevention, 12, 1-20.

Lester, D. (2000). Psychache, depression, and personality. Psychological Reports, 87, 940.

Lester, D., Beck, A. T., \& Mitchell B. (1979). Extrapolation from attempted suicides to completed suicides: A test. Journal of Abnormal Psychology, 88, 78-80.

Mills, J. F., Green, K., \& Reddon, J. R. (2005). An evaluation of the Psychache Scale on an offender population. Suicide and Life-Threatening Behavior, 35, 570-580.

Minkoff, K., Bergman, E., Beck, A. T., \& Beck, R. (1973). Hopelessness, depression, and attempted suicide. American Journal of Psychiatry, 130, 455-459.

Moscicki, E. K. (1997). Identification of suicide risk factors using epidemiological studies. Psychiatric Clinics of North America, 20, 499-517.

Moscicki, E. K. (1999). Epidemiology of suicide. In D. G. Jacobs (Ed.), The Harvard Medical School guide to suicide assessment and intervention (pp. 40-51). San Francisco: JosseyBass.

Moscicki, E. K. (2001). Epidemiology of completed and attempted suicide: toward a framework for prevention. Clinical Neuroscience Research, 1, 310-323.

Murray, H. A. (1938). Explorations in personality. New York: Oxford University Press.

National Institute of Mental Health (n. d.). Suicide in the U.S.: Statistics and prevention. Retrieved May 29, 2009 from http://www.nimh.nih.gov/health/publications/suicide-inthe-us-statistics-and-prevention/index.shtml. 
Nekanda-Trepka, C. J., Bishop, S., \& Blackburn, I. M. (1983). Hopelessness and depression. British Journal of Clinical Psychology, 22, 49-60.

Pereira, E. J., Kroner, D. G., Holden, R. R., \& Flamenbaum, R. (2010). Testing Shneidman’s model of suicidality in incarcerated offenders and in undergraduates. Personality and Individual Differences, 49, 912-917.

Robins, E., Schmidt, E. H., \& O’Neil, P. (1959). Some intercorrelations of social factors and clinical diagnosis in attempted suicide: A study of 109 patients. American Journal of Psychiatry, 114, 221-231.

Shahar, G., Bareket, L., Rudd, M. D., \& Joiner, T. E. Jr. (2006). In severely suicidal young adults, hopelessness, depressive symptoms, and suicidal ideation constitute a single syndrome. Psychological Medicine, 36, 913-922.

Shneidman, E. S. (1984). Aphorisms of suicide and some implications for psychotherapy. American Journal of Psychotherapy, 38, 319-328.

Shneidman, E. S. (1993). Suicide as psychache. The Journal of Nervous and Mental Disease, $181,145-147$.

Shneidman, E.S. (1999). Perturbation and lethality: A psychological approach to assessment and intervention. In D.G. Jacobs (Ed), The Harvard Medical School guide to suicide assessment and intervention. (pp. 83-97). San Francisco: Jossey-Bass.

Shneidman, E. S. (2005). Anodyne psychotherapy for suicide: A psychological view of suicide. Clinical Neuropsychiatry, 2, 7-12.

Silver, M. A., Bohnert, M., Beck, A. T., \& Marcus, D. (1971). Relation of depression to attempted suicide and seriousness of intent. Archives of General Psychiatry, 25, 573-576.

Statistics Canada (2011). Suicides, and suicide rate, by sex and by age group. Retrieved April 
22, 2014, from http://www.statcan.gc.ca/tables-tableaux/sum-som/101/cst01/hlth66aeng.htm.

Navaneelan T. (2012). Suicide Rates: An overview. Statistics Canada.

Thompson, E. A., Mazza, J. J., Herting, J. R., Randell, B. P., \& Eggert, L. L. (2005). The mediating roles of anxiety, depression, and hopelessness on adolescent suicidal behaviours. Suicide and Life-Threatening Behavior, 35, 14-34.

Troister, T., \& Holden, R. R. (2010). Comparing psychache, depression, and hopelessness in their associations with suicidality: A test of Shneidman's theory of suicide. Personality and Individual Differences, 49, 689-693.

Troister, T., Links, P. S., \& Cutcliffe, J. (2008). Review of predictors of suicide within one year of discharge from psychiatric hospitalization. Current Psychiatry Reports, 10, 6065.

Valente, S. M. (1994). Messages of psychiatric patients who attempted or completed suicide. Clinical Nursing Research, 3, 316-333.

Vredenburg, K., Flett, G. L., \& Krames, L. (1993). Analogue versus clinical depression: A critical reappraisal. Psychological Bulletin, 113, 327-344.

Weishaar, M. E., \& Beck, A. T. (1992). Hopelessness and suicide. International Review of Psychiatry, 4, 177-184.

Wetzel, R. D., Margulies, T., Davis, R., \& Karam, E. (1980). Hopelessness, depression, and suicide intent. Journal of Clinical Psychiatry, 41, 159-160.

World Health Organization (2002). World report on violence and health. Geneva: World Health Organization. 
Yen, S., Shea, T., Pagano, M., Sanislow, C. A., Grilo, C. M., McGlashan, T. H., Skodol, A. E., Bender, D. S., Zanarini, M. C., Gunderson, J. G., \& Morey, L. C. (2003). Axis I and Axis II disorders as predictors of prospective suicide attempts: Findings from the Collaborative Longitudinal Personality Disorders Study. Journal of Abnormal Psychology, 112, 375381. 


\section{APPENDIX A}

Table 1

Standardized Regression Coefficients for Predicting Change in Suicide Ideation from Change in Psychache Controlling for Change in Depression and Change in Hopelessness $(N=98)$

2-Year Follow-up Suicide Criterion

\begin{tabular}{|l|c|c|c|}
\hline & $\begin{array}{c}\text { Total Suicide } \\
\text { Ideation }\end{array}$ & $\begin{array}{c}\text { Suicide Motivation } \\
\text { Subscale }\end{array}$ & $\begin{array}{c}\text { Suicide Preparation } \\
\text { Subscale }\end{array}$ \\
\hline$R^{2}$ & $.61^{*}$ & $.63^{*}$ & $.53^{*}$ \\
\hline Predictor & & & \\
\hline Baseline BSS Scale & $.51^{*}$ & $.55^{*}$ & $.49^{*}$ \\
\hline Baseline Depression Scale & -.17 & -.16 &. .13 \\
\hline Baseline Hopelessness Scale & -.01 & -.17 & $-.25^{*}$ \\
\hline Baseline Psychache Scale & -.28 & -.20 & -.05 \\
\hline 2-Year follow-up Depression Scale & .10 & .11 & .05 \\
\hline 2-Year follow-up Hopelessness Scale & .16 & $.49^{*}$ & $.60^{*}$ \\
\hline 2-Year follow-up Psychache Scale & $.54^{*}$ & & \\
\hline
\end{tabular}

${ }^{*} p<.05$.

Note. Tests of significance are based on bootstrapping. Significance for the psychache regression coefficient at follow-up evaluates whether change in psychache correlates significantly with change in the BSS scale controlling for changes in depression and hopelessness. 